\title{
Creating Firm Disclosures
}

\author{
Amir Amel-Zadeh \\ Said Business School, University of Oxford \\ amir.amelzadeh@sbs.ox.ac.uk \\ Alexandra Scherf \\ Harvard Business School \\ ascherf@hbs.edu \\ Eugene Soltes \\ Harvard Business School \\ esoltes@hbs.edu
}

March 2019

Managers expend significant time and effort preparing disclosures about firm performance and strategy. Although prior literature has explored how variation in the style and presentation of disclosures impacts investors' perceptions of firms, little is known about how firms actually create these disclosures and how this process impacts presentation. Based on field data collected from nearly 200 firms, we show that there is considerable variation in who prepares disclosures, when they are prepared, and the amount of effort expended by different types of managers (e.g. legal, public relations/marketing, finance, investor relations, senior leadership). We find that these differences in organizational processes are associated with differences in the structure, style, and tone of $10-\mathrm{Ks}$ and conference calls. Ultimately, our investigation begins to illuminate how individual managerial efforts vary across firms and contribute to differences in public disclosures. 


\section{INTRODUCTION}

Managers of publicly traded firms spend considerable time and resources disclosing information to investors and other stakeholders outside the firm. Many disclosures-including 10Ks, 10-Qs, and 8-Ks - are mandated by regulators, but managers often supplement such filings with additional voluntary disclosures provided via conference calls, press releases, and private meetings with investors.

An extensive literature examines how differences in the style and presentation of disclosures — as measured by their tone, length, and complexity —impact investor perceptions and market responses. Much of this interest in examining the structural and textual components of corporate disclosures began with Li (2008), who showed that firms that employ more complex language have lower earnings persistence. Recent surveys on textual disclosures (e.g. Li 2010, Loughran and McDonald 2016) describe a variety of impacts associated with disclosure presentation and style, from increased analyst coverage for firms with less readable written disclosures (Lehavy, Li, and Merkley 2011) to higher litigation risk for firms with more optimistic disclosures (Rogers, Buskirk, and Zechman 2011).

Within this literature, most researchers focus on the economic impact of how disclosures are presented, and place relatively little emphasis on the internal processes that can lead to variation in disclosure style. Even when viewed in conjunction with the disclosure literature more broadly, little is known about the people who create disclosures-the firm managers in legal, public relations (PR)/marketing, finance, and investor relations (IR) — and how they contribute to the disclosure process. Some evidence suggests that individual managers can impact disclosure choices. For example, Bamber, Jiang, and Wang (2010) show that CEO and CFO backgrounds can influence voluntary financial disclosure choices. Yet, despite the ability of managers to individually contribute to the disclosure process, we do not have systematic evidence on how firms create disclosures and how differences in management and managerial processes potentially manifest in the textual and oral information ultimately conveyed to investors.

One major impediment to understanding who, when, and to what extent different managers are involved in creating disclosures is that disclosures are prepared privately within firms and the process is therefore not publicly observable. As Li et al. (2014) note in their investigation of how internal knowledge is revealed, researchers seeking to understand firm communication patterns have tended to rely on individual case studies to understand internal processes. "These case studies 
typically have unparalleled access to internal communications of the organization under study, an access inconceivable for a large sample of firms” (97). While case studies provide an opportunity to closely examine internal firm processes, individual cases do not offer sufficient power to engage in a more generalized and systematic empirical investigation. In this paper, we seek to overcome this hurdle through field study.

We began by developing seven case studies to understand the disclosure preparation process in detail. From these case studies, we identified numerous areas of variation across firms including the people involved, the timing of the processes, and the effort expended. Case development typically relies on researchers orally questioning managers in an open-ended fashion, which creates several logistical challenges to scaling. To remove some of these barriers and move from individual case studies to a larger body of field data, we narrowed our focus and developed a written questionnaire based on the detailed case studies. Through the questionnaire, we collected internal data for nearly 200 firms on who contributes to creating disclosures, how much time they expend, and when the preparation occurs.

Using this field data, we seek to answer two questions. First, do firms vary in how they create disclosures? As many companies rely on benchmarking surveys to align their practices with other firms, there is potentially significant homogeneity in practices across firms, reducing the opportunity for exploring differences in practices. Second, to the extent that there are differences, is variation in internal firm processes associated with publicly observable differences in output? Specifically, we examine if variation in how disclosures are prepared is associated with differences in the presentation, style, and tone of the management discussion and analysis section of public reports (MD\&As) and conference calls.

Our investigation yields a number of insights to both of these questions. First, despite firms' tendencies to benchmark, we show that there is considerable variation in how firms prepare disclosures. For the MD\&A, we find that the investor relations officer (IRO, described in some literature as the "chief disclosure officer") often takes a more limited role in the drafting process compared to other senior executives including the $\mathrm{CFO}$ and legal officers. We also find some firms where $\mathrm{PR} /$ marketing managers and even board members take a leading role in creating the MD\&A. Firms further vary in how far in advance they begin preparing the MD\&A—from one week in advance to seven or more- and how much they rely on the prior year as a template. 
In planning for conference calls, we find that only a third of firms collect questions in advance from analysts and investors and prepare potential responses. As would be expected from the prior literature, the vast majority of firms employ a script during the presentation portion, but we also find - in contrast to prior research that posits that the Q\&A is largely extemporaneousthat over half of firms employ some form of scripting during the Q\&A portion of the call. On average, the CFO spends nearly twice as many hours as the CEO preparing for conference calls, but we also find some firms where senior leadership does little to no advance preparation.

Creating disclosures takes considerable time, and we examine when firms begin this process in comparison to when they are aware of the preliminary or finalized quarterly financial results. We find that the majority of firms (65 percent) of the sample begin preparing for the quarterly conference call in advance of even preliminary financial results being known.

Ultimately, we show that many groups outside of IR, including PR/marketing, are involved with disclosure preparation, and this varies significantly across firms. Our analysis also shows that some perceptions in the academic literature-for example, that conference call Q\&A tends to be unscripted and extemporaneous - are not consistent with actual practice.

In our second series of tests, we examine whether differential engagement by managers is associated with differences in the presentation, style, and tone of disclosures. In line with their department's goals of improving perceptions of their firms, we find that when PR/marketing is more involved in the MD\&A and conference call preparation, the call tends to be less negative and the MD\&A more optimistic. We also find that greater involvement by legal departments reduces the use of more descriptive positive and negative language that can create greater liability for firms. Furthermore, we find that involvement by PR/marketing impacts the year-over-year MD\&A similarity by reducing the number of changes, and therefore reducing the informativeness, as documented in prior work.

Lastly, we find evidence that variation in the preparation process is associated with variation in presentation and tone. Executives who employ a more improvisational style in the conference call Q\&A tend to answer more questions and use more self-serving language (i.e. avoid the use of "we"). Moreover, when executives do not rely on prepared responses in the Q\&A, they tend to use more negative and less positive language, reflecting a less tailored description that employs more descriptive language. We also find that managers who prepare their MD\&As further in advance tend to use less complex language (as indicated by FOG and BOG) in their MD\&A. 
Overall, our findings provide preliminary evidence on the ways in which disclosure preparation processes are associated with how information is publicly conveyed to markets. Specifically, we find that there is considerable variation in which managers are involved in creating corporate disclosures, and some types of managers are more involved in the disclosure creation process than is commonly assumed in the literature. Broadly, our evidence is supportive of prior research where the presentation, style, and tone of disclosures is not simply a reflection of the firm economics, but also a reflection of the individual managers involved in the process. By showing that this extends beyond senior management (i.e. CEO and CFO) to other departments (e.g. $\mathrm{PR} /$ marketing, legal, IR, etc.) and further relates to the timing of and effort expended on the disclosure, our findings indicate that how disclosures are presented captures organizational factors related to people rather than to firms.

Our paper offers a number of contributions to the disclosure literature. Perhaps most significantly, our analysis explicitly shows that managerial effort to prepare disclosures varies significantly across firms. In doing so, we build on recent work by Bushee, Gow, and Taylor (2018), who show that interpreting the readability of a firm's disclosures requires understanding the underlying economics of the firm and its managers. We further demonstrate that, to the extent that managerial time and effort vary, so too can the output of those activities. ${ }^{1}$ In this way, our investigation seeks to refine the conversation on corporate disclosure, which often speaks of "firms disclosing information.” However, firms are not endowed with the ability to create disclosures; rather, it is the firm's managers who ultimately produce them.

Second, given the variation we observe in disclosure practices across firms, researchers should be cautious in drawing inferences about incentives, potential biases, and obfuscation without knowing who is involved in the process. For example, while it is possible that an executive's decision to employ certain language is driven by a self-serving attribution bias, it may also be the case that PR/marketing managers—who seek to make the firm and its managers look more attractive - were more heavily involved in preparing the executive's remarks. Researchers (e.g. see page 159 in Li (2010)) have often been aware of this distinction in drawing inferences, and careful to note that without knowing who prepares disclosures, these hypotheses cannot be separated. Our field data indicates that more heavily researching who prepares disclosures is likely

\footnotetext{
${ }^{1}$ A number of recent papers have examined the amount of senior executive time expended on different activities and how that relates to performance (see Bandiera et al. (2017) and Porter and Nohria (2018)).
} 
to help develop a better understanding of the underlying incentives behind particular language choices.

Our paper also offers a methodological contribution by demonstrating how one can collect data on internal firm processes in "large sample." Accounting researchers have tended to rely on proxies to examine behavior or processes that are not accessible in public data sets. Yet, it is possible to collect this information directly from managers, revealing more information and reducing the potential noise and measurement error that accompany the use of proxies (e.g. see Bloomfield, Nelson, and Soltes 2016). To the extent that researchers seek to collect information about firm processes — rather than individuals or their judgements— such data collection is subject to less institutional restrictions, thereby reducing the challenges faced by researchers. ${ }^{2}$

From a regulatory standpoint, our investigation contributes to the question of design and "disclosure efficiency," i.e. the effectiveness of disclosures in communicating the firm's position and priorities. Bloomfield (2012) explains the obstacles associated with managers disclosing the most salient information to investors in a concise fashion and proposes appealing to theories on how information is efficiently conveyed in human communication. In particular, he points out that current regulation encourages firms to over-share, or disclose any information that may be relevant to investors. This diminishes investors' ability to ascertain that the firm has freely chosen to offer that information. Put differently, if firms had greater ability to "elevate" some information above others, this would allow investors to better understand what information the firm wants to highlight. However, in this paper we argue that firms do not prepare disclosures as a monolith, but rather as a group of individuals with diverse incentives. Our field data suggests a wide variety of different managers are involved in the disclosure process, each bringing with them their own preferences (e.g. marketing managers will approach the disclosure process with a marketing lens). Variation in preparation norms may also generate variation in how firms ultimately "elevate" information—resulting in firm disclosures that do not necessarily reflect one clear firm vision but rather a noisy amalgamation of different internal interests. By recognizing these diverse disclosure creation processes, regulators may be better equipped to design disclosure rules that encourage more consistent "elevation" of relevant corporate information and that are less sensitive to variant disclosure preparation practices.

\footnotetext{
2 To the extent that a researcher is simply collecting data on firm practices, Institutional Review Boards (IRBs) would deem the work as non-human subjects research and outside their scope. To the extent that some anonymous data was collected that related to individuals, it would likely be exempted under 45 CFR 46.101(b)(2).
} 
While our approach permits an illumination of internal firm processes, it is subject to several limitations and caveats. Although the sample size in this paper is considerably larger than other studies using field-based data (e.g. see Park and Soltes 2018), by comparison to most archival-based work in financial accounting, the sample is still only moderate in size. As a result, it is possible that we lack the power to identify all the potential relationships between the internal disclosure creation process and the structure of disclosures, given the noise and variability in the textual outcome variables. In addition, our field-data collection focused on gathering information about a firm's average disclosure creation process over a single year (i.e. 2016) rather than on a firm's quarter-to-quarter practice over time. Ideally, we would have been able to gather the specific practices from quarter to quarter, to allow within-firm variation (e.g. good vs. bad quarters). Practically, such specificity could only be collected by embedding some monitoring mechanism within firms (as in Park and Soltes 2018). As this would have limited the sample size due to cost considerations, we opted for greater breadth by collecting process data at the firm level. However, future researchers would benefit from ascertaining the amount of intra-firm variation in disclosure processes.

\section{MANAGERS AND THE CORPORATE DISCLOSURE PROCESS}

In this section, we describe the background - both institutionally and from the research literature — of the disclosure creation process and its impact on market reactions. In 2.1, we describe the regulatory environment that leads to differences in the disclosure process. In 2.2, we provide an overview of the prior research that shows how the content, readability, structure, and style of disclosures impact investor and market responses. In 2.3, we provide two case studies describing how firms differ in their disclosure creation process. Finally, in 2.4, we explain our hypotheses that motivate our field-data collection and analysis.

\subsection{The Regulatory and Institutional Environment Surrounding Corporate Disclosure Creation}

Firms are mandated to publicly disclose information about their operations, performance, and strategy. Many of these disclosures, like annual reports (10-Ks), quarterly reports (10-Qs), and intermediate updates (8-Ks) arise from regulatory requirements (e.g. the Securities Act of 1933). 
These requirements provide fairly detailed guidelines, leading to some homogeneity in the types of information disclosed by firms. Supplementing these disclosures, firms often voluntarily disclose additional information in other venues. Quarterly conference calls hosted by management when releasing earnings is one prevalent form of these supplemental voluntary disclosures.

Although regulators provide guidance on what information is required to be disclosed, in what form (e.g. according to US GAAP), and when it should be disclosed, there is little to any guidance on how these disclosures should be created. While regulations may prescribe that certain people must give their assurance (e.g. CEO/CFO certification under Section 302 of the SarbanesOxley Act), such attestations provide little insight into the relative effort and timing of each manager's involvement in creating the disclosure. For instance, a CEO may only feel comfortable certifying the financial statements by becoming heavily involved with discussions during the entire report preparation, or may only seek to validate once the financials are effectively finalized. The lack of requirements means that managers are effectively able to choose the process that they feel is more appropriate for the creation of disclosure documents as long as the final document conforms to expectations (e.g. regulatory with the SEC, independent auditors). Moreover, while regulations describe what needs to be disclosed, the specific structure and tone of those disclosures are also left to managerial discretion.

\subsection{The Impact of Disclosure Structure and Tone}

Over the past decade, a considerable body of research has investigated how the presentation, structure, and style of disclosures impacts market responses. ${ }^{3}$ Recent surveys on

\footnotetext{
${ }^{3}$ Our goal is to contextualize this paper within the accounting literature on disclosure as a means of communication between the firm and the market. However, it is worth noting other related streams of research on corporate communication and communication styles in behavioral economics and finance. Recent trends in behavioral economics highlight the need to recognize human cognitive biases that can impact decision making, including communication choices (Kahneman 2003). One critical component of communication is sentiment - the attitude or view underlying statements of discourse. In their review of the finance literature on textual sentiment, Kearney and Liu (2014) explain that "sentiment is now understood to be articulated in many forms of human discourse, public speeches, news reports, blogs and other forms of written, spoken and visual communication.” Researchers in finance (as in accounting) have capitalized on textual analysis as a tool for quantifying sentiment and attempting to measure psychological traits or biases in individuals, firms, and other market participants. Main findings from this literature include the following: (1) negative sentiment tends to have a larger impact on market prices than positive sentiment, (2) sentiment tends to have more immediate or short-term effects on market prices, and (3) tone is associated with firm characteristics and performance, but (4) stock returns can also be used to predict sentiment—suggesting communication style may be both driven and shaped by performance (Kearney and Liu 2014). By providing field evidence of how managerial preparation may impact disclosure sentiment, our study builds upon these literatures on communication style and tone in economics and finance.
} 
textual disclosures (e.g. Li 2010, Loughran and McDonald 2016) describe a variety of these impacts, associated with the disclosure presentation and style which can be categorized into two broad themes. First, structural cues from textual disclosures appear to provide insights into the quality of financial disclosures and performance. Studies have found that firms with more readable annual reports tend to have lower analyst dispersion and greater forecast accuracy (Lehavy, Li, and Merkley 2011). Brown and Tucker (2011) show that firms with larger year-over-year modifications to their MD\&A statements have larger stock price responses to their 10-K filing. Second, the literature suggests that managers' communication style or tone may also provide insights into managerial and corporate decision making. For example, Li et al. (2014) find that CEOs tend to speak less relative to other executives on conference calls when their relative knowledge in a setting is low, and CEOs who speak more tend to be paid more than their quieter peers. This complements previous studies on links between disclosure sentiment and managerial behavior: Mayew and Venkatachalam (2012) demonstrate that the affective tone of executives during the Q\&A portion of earnings conference calls impacts subsequent investor reactions; Rogers, Buskirk, and Zechman (2011) show that firms with more optimistic disclosures tend to exhibit higher litigation risk; and Larcker and Zakolyunkina (2012) provide evidence that executives who utilize more deceptive language during conference calls are more likely to engage in deceptive accounting practices (e.g. SEC-sanctioned restatement). Overall, as these examples indicate, this line of research shows that the structure and tone of firm disclosures, whether in regulatory documents (e.g. 10-K, 10-Q) or voluntarily disclosures (e.g. quarterly earnings conferences calls), are economically significant.

Some observations in this literature also indicate that the structure and tone of disclosures are driven by factors related to the companies producing those disclosures. For instance, Brown and Tucker (2011) find that larger economic shifts are associated with larger year-over-year MD\&A changes. Yet, researchers have struggled to elucidate the specific mechanisms driving stylistic variation. As Loughran and McDonald (2016) explain, “[R]esearchers face the problem of separating the business and the document. These issues are intertwined because the document attempts to describe the economic reality of the business” (1198). As an example, a disclosure document could have a low readability score because managers seek to obfuscate news, or instead because more complex language is needed to describe an inherently more intricate set of transactions. Bushee, Gow, and Taylor (2018) address this challenge by decomposing a 
disclosure's structure into two components, one related to the linguistic complexity associated with managerial obfuscation and the other related to the business's complexity. By showing that there are competing factors that contribute to differences in the language and style of disclosures, Bushee, Gow, and Taylor (2018) demonstrate that interpreting the readability of a firm's disclosures requires understanding the underlying incentives of the firm and its managers.

Bushee, Gow, and Taylor (2018) indicate that managers can influence the readability and style of disclosures, but questions still remain about how, who, and in what manner managers impact firm disclosures. To the extent that language-whether written or spoken-reflects the individual incentives and goals of those who create the communications, the tone and structure of disclosures are also likely to vary depending on who prepares those disclosures within an organization. Specifically, we hypothesize that the structure of conference calls and the style of language in an annual report are reflective of the effort, preparation, and coordination among different people within an organization. Put simply, the more time and effort a specific manager expends in creating a disclosure, the more distinctly that disclosure will reflect that manager's experience and incentives. ${ }^{4}$ For instance, to the extent that marketing managers become involved earlier and more intensively in the preparation of a conference call script, we expect the remarks on the conference call to more closely reflect the objectives and perspective of marketing managers, whose job is to positively communicate the firm's position.

Among practitioners, the ways that individual managers impact the form and style of disclosures is a popular topic of discussion. Practitioner publications (e.g. IR Update, IR Magazine) often provide articles on how to "effectively" prepare disclosures. For example, one article on how firms should prepare for conference calls describes practices at various companies. Nils Paellmann, the head of IR for T-Mobile, explained, “[W]e typically have three or four earnings prep sessions with top leadership where we also review the document together.... [I]n addition, we do one or two earnings calls rehearsals where we ask top management the toughest questions analysts are most likely to ask" (Walsh 2017). While there is a rather voluminous amount of discussion of "best practices" in the practitioner literature, there is no clear consensus or understanding of what the impact of different practices actually is. One reason for this is that most

\footnotetext{
${ }^{4}$ Graham, Harvey, and Rajgopal (2005) examine the incentives of senior leaders in the context of financial reporting and find that managers often make decisions that align with individual incentives rather than long-term value creation for their firms. Ge, Matsumoto, and Zhang (2011) examine how CFO style impacts accounting choices.
} 
of these articles provide "benchmarks," which simply describe what other firms do rather than indicating what the effect of including different people or exerting differential effort is on the final disclosures. ${ }^{5}$ In this regard, it is not even clear from the practitioner literature if differences in effort or preparation actually have an economic impact on the ultimate disclosures since the focus is simply on inputs (e.g. how much time a CEO spends preparing for the call) rather than the outputs (e.g. the impact on how a CEO actually communicates on a call).

In contrast to the practitioner literature, the academic literature has given relatively little attention to the roles that individual managers play in the disclosure process. One factor likely contributing to this lack of attention is that the preparation process is conducted privately by firms and is therefore not readily observable to researchers. The one area related to the preparation process that has attracted academic attention-and is publicly observable in some instances-is the role of attorneys. Bozanic, Choudhary, and Merkley (2016) find that the use of an external legal counsel improves readability and increases the likelihood of cautionary letters in annual reports. Cohen, Malloy, and Nguyen (2016) show that firms that hire outside attorneys create disclosures that appear more similar year-over-year, and the findings in Hopkins, Maydew, and Venkatachalam (2015) suggest that more highly paid general counsels tend to be at firms that have lower financial reporting quality and more aggressive accounting practices.

While attorneys play a significant role in the disclosure creation process, they constitute only one of many departments of an organization that contribute toward creating firm disclosures. To help illustrate the roles of different departments and individuals, we present two case studies that demonstrate the variable time and effort that different managers contribute to creating disclosures.

\subsection{Differential Involvement of Managers: Two Case Studies}

As part of our initial work in creating this project, we engaged with IROs to understand, in detail, how different managers become involved in the disclosure creation process. ${ }^{6}$ From these interactions, we were able to acquire internal documents describing the disclosure creation process

\footnotetext{
${ }^{5}$ For example, to what extent the efforts of the CEO in preparing for the earnings call affect the linguistic characteristics and economic outcomes of the call remains unclear from this work.

${ }^{6}$ We acquired the disclosure schedules for seven publicly traded firms in the spirit of Simons (2010) and Li et al. (2014), 97. We were provided with this information under the agreement that we would keep the firms' names confidential.
} 
and timeline. We found that firms had considerable variation in their processes. Some firms had explicit schedules (including timing, people involved, etc.), while others only created a list of tasks they were required to complete each period. In Figure 1, Panels A and B, we provide two of these schedules: the first for a mid-capitalization industrial company (Firm A) and the second for a small-capitalization technology company (Firm B). We specifically present these two cases studies because we have comprehensive information about both the timing and people involved in the disclosure processes for each company. ${ }^{7}$

A variety of differences are apparent when comparing the preparation processes between the two firms. Firm A spends approximately 5 weeks creating its quarterly earnings disclosures (e.g. conference call, 10-Q, press release), whereas Firm B spends less than 3 weeks. At Firm A, the general counsel becomes involved in drafting the financial guidance from the beginning, whereas in Firm B, the General Counsel only becomes involved in the earnings release and conference call script in the final week. Moreover, for Firm B, PR/marketing is involved with feedback and guidance for the conference call script, whereas in Firm A, PR/marketing is not involved in any part of the disclosure creation process (they simply disseminate information, but are not actually involved in its creation). While these differences emerge, there also seem to exist a number of similarities. In particular, both firms prepare scripts for discussion on the conference call, and compile possible Q\&A questions that management expect to receive. The CFO is closely involved in this script creation at both firms. The differences and similarities in these processes served as motivation to collect field evidence and focus our empirical analysis around these dimensions of timing and effort by particular managers.

\subsection{Investigating the Disclosure Creation Process}

Our analysis examines two areas around disclosure creation. First, we investigate if the process for creating disclosures_-focusing on MD\&As and conference calls—varies across firms. We examine this variation across three dimensions: who prepares the disclosures, the amount of effort expended by different types of managers, and when the preparation occurs. Some anecdotal

\footnotetext{
${ }^{7}$ For the other case studies, the documentation we acquired did not consistently provide time and people involved, instead focusing on tasks, with time and people being decided at the time of the disclosure event. For example, one firm recorded as a step in 10-K and 10-Q preparation that “edits made to document are proofed by responsible parties.” As we seek to focus individual roles, such broad and vague descriptions do not offer sufficient insight into who is specifically (and necessarily) involved in the process and when they became involved.
} 
evidence, such as the cases described in Section 2.3 and published case studies (e.g. Simons 2010), suggests that we ought to expect significant variation in practices across firms in all three dimensions. On the other hand, the practitioner literatures indicates that many, if not most, firms rely on benchmarking to determine processes (e.g. using benchmarks from the National Investor Relations Institute, NIRI). To the extent that people rely on similar benchmarks and follow their peers, the process should show little variation across at least some of these dimensions across firms. We rely on the field data we collect to examine if, and in what regard, there is variation in the disclosure creation process.

Our second series of analyses examines how potential differences in processes are associated with the presentation of public disclosures. Practitioner guides often describe how different individuals contribute to the corporate disclosure process by bringing their own perspectives and experience. For example:

Although the Investor Relations Officer is often responsible for and usually leads the development of the annual report, there are many people involved in the process. They often comprise ... the finance department, people from the corporate communications and legal departments and ... the marketing department. During various stages of the development process, other people will become involved, such as the CEO, CFO and chief legal officer. Everyone contributes their own perspectives on the business... (J.P. Morgan 2017, 29).

Although different groups, including PR/marketing, IR, and legal, may contribute to creating conference calls and the MD\&A, it is unclear whether their individual objectives will necessarily be reflected. For example, PR/marketing seeks to present the firm in a more positive light, whereas legal typically seeks to have more conservative disclosures. ${ }^{8}$ Moreover, the reason why one group (e.g. finance or legal) may contribute more than IR at a particular firm does not necessarily indicate a desire to leave a stronger mark on the disclosure process. For instance, legal officers may simply have more relevant background and qualifications compared to IROs. While at some firms the IROs act as sophisticated analysts, at others they primarily serve as communications professionals

\footnotetext{
${ }^{8}$ We expect that PR/marketing involvement tends to lead to more positive representations of the firm. This is motivated by the findings of Solomon (2012) that firms engaging external IR or PR firms tend to experience greater positive media "spin” of their positive press releases as opposed to negative press releases. We also predict that legal personnel tend to seek more conservative disclosures based on prior accounting research, in particular Bozanic, Choudhary, and Merkley (2016), who find that increased external legal involvement is associated with decreased detail and frequency of disclosure. Increased legal involvement is further associated with increased readability and increased qualified or cautionary language in future annual reports. By stating that increased legal involvement in the disclosure process is associated with "more conservative disclosures," we refer to disclosures that tend to be more cautious.
} 
arranging interactions with more senior management. To the extent that these different groups substitute for one another, we should not find a noticeable impact on the presentation, style, and tone of conference calls and the MD\&A based on their contributions.

Practitioner guides also suggest elements related to timing that could impact the disclosures. As an example:

Timeliness also reflects well on the management team and IRO. Start the development process as early as possible; for companies whose fiscal year coincides with the calendar year, many get started in September (J.P. Morgan 2017, 30).

The timing and amount of preparation could simply reflect a balancing of tasks within the firm and therefore have little ultimate impact on the disclosures. Alternatively, earlier timing could reflect greater priority for those working on the disclosures, who might therefore have greater investment in aligning those disclosures with their objectives. To investigate this, we examine whether the contributions of different people, the amount of effort they expend, and timing are associated with commonly examined textual dimensions (e.g. positive language, length, similarity, and FOG/BOG) within conference calls and MD\&A disclosures.

\section{FIELD DATA COLLECTION AND DESCRIPTION}

One of the main obstacles associated with this project was collecting data on the internal firm processes that managers employ to create their firms' disclosures. Oral interviews with firm managers, as is done in building case studies, can elicit significant detail but imposes significant time commitments for each firm (e.g. arranging meeting times and locations, engaging in dialogues with multiple people, etc.). In order to build the desired "large sample" to study textual outputs potentially associated with different disclosure creation processes, and to support the generalizability of the investigation, we understood that approaching the data collection using a case-based approach would be infeasible. At the same time, we sought to capture several dimensions of firms’ internal processes, as is typical of cases.

To understand the private disclosure creation process in more detail, we began by developing seven case studies, two of which are described in Section 2.3. We found three dimensions across which firms made different decisions. These were the managers/teams involved in the disclosure creation process, the timing in which different parts of the disclosures were created, and the amount of effort expended by different mangers. We found these dimensions 
captured the greatest differences in the detailed cases, and decided to use these dimensions as the focal points to collect data from additional firms.

To scale our data collection, we developed a questionnaire based on our case studies. The questionnaire aimed to gain data similar to what could be obtained by speaking with managers in person for case development. ${ }^{9}$ Our questionnaire differed from surveys conducted by accounting researchers in two significant ways. First, our focus was on collecting data about firm practices rather than subjective assessments of how managers felt or what they believed about a particular situation or hypothetical scenario. In this way, our interest was the firm rather than the respondent. ${ }^{10}$ Second, as is typical with cases where researchers may need to speak with multiple managers to understand a phenomenon, our questionnaire posed several questions that potentially required input from different managers or divisions. As this placed a larger burden on respondents, we sought to be concise in the number of questions that were asked. In addition, we coded each survey to identify the firm, thereby avoiding the need to ask basic firm-level information regarding size, industry, etc. ${ }^{11}$ Ultimately, in spite of the effort required by managers to complete our questionnaire, we found that many were willing to engage based on the response rate.

To develop our questionnaire, we first created a draft set of questions that reflected a number of the most significant issues we observed from the cases. The draft questions were shared with two experienced IROs who provided us detailed feedback on the framing and language used in the questions. Based on their feedback, we iterated the design until the questions would allow us to capture the desired information while also conforming to the expectations of potential respondents about the types of information that they would reasonably be expected to be able to answer. The final questionnaire we utilized is provided in Appendix 3.

We sent our questionnaire to 500 randomly selected firms in July 2017. To form our list of sample firms we began by considering all US-based (i.e. incorporated and headquartered in the United States) public companies that were trading common stock (as of December 31, 2015) and appeared in both the CRSP and Compustat databases. We then narrowed our list of potential sample firms to only include entities that held four quarterly conference calls during the fiscal year 2016. These criteria left us with a pool of 1,406 potential sample firms, which we stratified into

\footnotetext{
${ }^{9}$ In a related area, Bloom et al. (2016) discuss the potential benefits and costs of open- versus closed-ended questions.

${ }^{10}$ Studies that ask data about firms rather than people are moreover exempted from IRB oversight. Our study underwent a formal IRB review by Harvard University (IRB17-0939) and was exempted by the Harvard IRB office under 45 CFR 46.101(b)(2).

11 The firm code was printed in a small font in the bottom corner of the final page.
} 
four quartiles based on market capitalization. We then used Stata to randomly draw 125 firms from each quartile, for a sample of 500 firms total.

As the point person for much of a firm's disclosure program, the firm's IRO was our primary contact for the questionnaire. ${ }^{12}$ We manually collected business addresses for the IROs for all firms in our sample. There were 78 firms for which we could not identify or obtain contact information for either the IRO or a chief officer tasked with overseeing IR. These included cases where the company employed external IR services. These 78 firms were replaced with others randomly re-drawn from their respective market capitalization quartiles in the potential sample pool of 1,406 firms (less the 422 firms already selected with available contact information). This resulted in our final sample of 500 US-based public firms, which all held quarterly 2016 conference calls and had available contact information for executives in charge of their IR functions. Our sample process is also detailed in Appendix 2.

After finalizing our sample firms and firm contacts, we began the process of distributing our survey and compiling responses. Although the majority of the questions we asked were factual in nature (i.e. statements of information about internal firm practices), to avoid potential biases associated with responding to questions in a written survey, we generated four versions of our survey (A, B, C, and D) with differing orders for judgement-based questions, and randomly assigned these versions across firms. We mailed paper copies of our survey, along with a one-page letter explaining the purpose of the study, to our sample firms in June 2017. Besides pre-paid postage and envelopes for returning the survey, the mailings did not include any financial or nonfinancial incentives for participating in the study. In late August 2017, we followed up with nonresponders by placing phone calls and sending personal e-mails including a link to an identical online version of our questionnaire. Our online questionnaire also came in four versions (A, B, C, and D) corresponding to the paper versions. We received an additional 39 completed questionnaires online.

\footnotetext{
12 Sending the questionnaire to any particular manager, rather than "the firm," has the potential to induce bias associated with that manager. Ideally, the questionnaire would have been provided to several managers to assure that the responses reflected an aggregate view of the preparation process and not a "self-centered" view where the manager —in this case the IROoveremphasizes his or her influence. Empirically, however, we have some comfort that the IROs that served as point persons within firms for our surveys did not state that they were the most important individuals for disclosures, contrary to a common assertion in the practitioner literature (describing the IRO as the "chief disclosure officer"). Specifically, IROs do not appear among the top three preparers of MD\&A disclosures or conference call presentations as frequently as other managers such as CFOs or those in PR/marketing or internal legal departments.
} 
Ultimately, we received 193 responses to our survey, including paper and online responses, for a total response rate of 39 percent. Although this response rate is lower than for a case-based approach, it is considerably higher than in most academic studies that rely on surveys to collect data from managers (with response rates ranging from 5 to 15 percent). ${ }^{13}$

To calculate our outcome variables of disclosure characteristics such as tone or length, we performed a textual analysis on each firm’s 2016 quarterly earnings conference call transcripts and MD\&A sections from the firm’s 2015 and 2016 annual reports. One challenge in conducting a survey of disclosure practices is that managers may provide responses for different time periods depending on when exactly they complete the survey and, even more significantly, their memory. Several questions in the survey asked managers to estimate time or effort, which they likely recall from recent disclosures, but not necessarily the most recent. This motivated our decision to average responses across disclosures (across all four 2016 conference call disclosures, and across both 2015 and 2016 MD\&A disclosures) to produce one value per firm for the conference call analysis and one value per firm for the MD\&A analysis. While there are drawbacks to this approach (notably, we cannot study within-firm variation), this allows us to avoid the potentially more significant problem of not knowing which specific period or combination of periods the respondent is referring to in his or her response. Other control variables and firm characteristics, such as size (logged market capitalization) and market-adjusted returns, were calculated using data from CRSP and Compustat. All variable definitions are provided in detail in Appendix 1.

\section{VARIATION IN MANAGEMENT}

We begin our analysis by examining whether and in what circumstances variation in the preparation of conference calls and MD\&As arises. The data from our questionnaire focuses on three dimensions of disclosure preparation: who prepares, what effort they expend, and the timing of this work. ${ }^{14}$

\footnotetext{
${ }^{13}$ Examples of response rates from academic accounting surveys include Brown et al. (2018): 14.5\%; Dichev et al. (2013): 5.4\%; Brown et al. (2015): 10.9\%; Graham, Harvey, and Puri (2016): 13.4\%; and Graham, Harvey, and Rajgopal (2005): 10.4\%.

${ }^{14}$ For brevity, we present selected data from the field questionnaire, which provide insights into the variation in disclosure preparation practices among firms. Our complete survey included additional questions that are not examined in detail here. We provide the complete summary statistics for all questions in our online appendix.
} 


\subsection{Conference Call Data}

Table 1 examines our field data on preparation for quarterly earnings conference calls. In Panel A, we find that most firms (52 percent) begin 3-4 weeks in advance, but nearly a third (31 percent) begin only 1-2 weeks in advance. Preparation may include drafting materials for the presentation portion of the call as well as drafting responses to questions likely to be raised by analysts and investors on the call.

In Panel B, we examine the three types of materials commonly prepared for the presentation portion of the call: scripts, slides, and outlines. We find that the vast majority of firms (92 percent) prepare a script for the presentation. We also find that slides-which are often posted to the firm's website during or after the call—are also commonly prepared, by 47 percent of firms. Outlines, for internal and/or external distribution, are somewhat less commonly prepared by 22 percent of firms. The Venn diagram in Panel B shows the overlap between use of these materials, with firms that prepare multiple materials most commonly using both a script and slides, followed by using all three elements.

In Panels C-E, we examine managers’ preparation for the Q\&A portion of the call. A voluminous practitioner literature explains how managers “ought” to prepare for earnings conference calls by explaining how most firms prepare (i.e. benchmarking). As an example:

A few weeks prior to the earnings conference call, consider calling key investors and analysts to ask them what key issues they would like management to focus on during their remarks. In addition to helping keep the conference call focused, this feedback can be used to develop the Q\&A document discussed above (J.P. Morgan 2017, 34).

Despite certain efforts in the practitioner literature to nudge managers to similar practices, we actually find some areas with considerable variation in how firms prepare. As shown in Panel C, approximately half of firms (59 percent) script most of their Q\&As, and an additional 7 percent note that theirs are completely scripted. Thus, there is variation in the amount of scripting for the Q\&A section. However, mitigating this variation to some extent is the finding, shown in Panel D, that 92 percent of firms prepare responses to potential questions. Thus, even those firms that indicate they rely on a more "improvised” style for the Q\&A still often have prepared responses available. Notably, this contrasts somewhat with Lee (2016), who uses a proxy to infer whether managers are scripting calls. Lee (2016) notes that "the [management discussion] portion of the 
call is often referred to by managers as the 'prepared remarks' and likely represents a written narrative intended to be read out loud. In contrast, the Q\&A is more likely to be extemporaneous” (232). Our field evidence suggests that even the Q\&A portion of the call for many managers is heavily scripted, with the vast majority of firms preparing responses and many scripting the Q\&A session to a significant extent. Furthermore, in contrast to the suggested "best practice" in the practitioner literature, Panel E reveals that only a minority (36 percent) engages with analysts and investors to discuss topics of interest ahead of the call.

In Panel F, we describe the amount of time spent in preparation by the two primary speakers on conference calls, the CEO and CFO. CEOs spend, on average, 9 hours preparing, and CFOs spend 16 hours. The lengthier preparation by CFOs is statistically significant at the 1 percent level (t-stat.= 4.9).

Brown et al. (2018) find that planning for the presentation portion of the conference call is among the most important activities for IROs. We find that the IR team is the most involved, on average, in drafting the introductory remarks in Panel G. The CFO and CEO are the second and third most involved in this drafting process. The difference in involvement between IR and the CFO is marginally statistically significant at the 10 percent level (t-stat.=1.6), whereas the difference in involvement between the CEO and the CFO is significant at the 1 percent level (tstat.=-3.9).

A growing body of research examines how managers engage offline with investors. Soltes (2014) finds that IR often calls analysts immediately after the conference call to address any additional questions analysts have. We also find that the majority of firms speak privately with investors and analysts after the calls. Specifically, 98 percent of firms report following up with sell-side analysts after the call, and 97 percent report following up with buy-side investors.

Overall, we find significant variation in several disclosure preparatory practices across firms, including whether a firm speaks to investors ahead of time and the relative amount of time different executives spend preparing for their calls. However, we observe similarity across firms in predominantly scripted presentations and prepared responses for the Q\&A portions of conference calls.

\subsection{0-K/MD\&A Data}


In Table 2, we collected information regarding the preparation involved in creating both the MD\&A and broader 10-K filings. In Panel A, we find that the initial draft of the MD\&A typically originates in the finance department (73 percent of firms). Notably, while IROs are often viewed as the "chief disclosure officers" (NIRI 2014, as discussed in Brown et al. 2018), IR officers are rarely the initial authors of the MD\&A, as we find that they begin drafting the MD\&A in less than 4 percent of firms. In Panel B, we find that most firms begin drafting the MD\&A 5 or more weeks in advance. However, more than a quarter of the sample (26 percent) begin less than a month ahead of time, with 4 percent of firms beginning the process only 1-2 weeks in advance. Later preparation is also associated with a greater frequency of revisions. In particular, untabulated results reveal that late MD\&A preparers had a mean of 1.8 revisions per week, compared to early preparers with .9 revisions per week, which was statistically significant at the 1 percent level (tstat.=6.2). Thus, while the aggregate number of revisions was similar between those who prepared early versus late, those preparing later had to more aggressively revise the document to complete it by the expected filing date.

We also find, in Panel $\mathrm{C}$, that the majority of firms have a strong reliance on the prior year's MD\&A as a template. We find only one firm in our sample where managers do not rely on the prior year's MD\&A at all. The tendency for most firms to begin with the prior year's MD\&A as a template for the current year is one reason why seemingly minor changes (e.g. the addition or subtraction of particular topics or risks) have economic significance (Brown and Tucker 2011; Cohen, Malloy, and Nguyen 2018).

As a way to expedite the drafting of the MD\&A, firms that begin drafting the MD\&A later could rely more heavily on the prior year's MD\&A. However, we actually find the opposite situation, in which firms that begin drafting the MD\&A earlier are more likely to strongly rely on the prior year's MD\&A as a template. In particular, untabulated results show that 38 percent of those that strongly rely on the prior year's MD\&A begin 7+ weeks in advance, whereas only 26 percent of those that weakly rely on the prior year's MD\&A begin this early. This difference is statistically significant at the 10 percent level $\left(\chi^{2}=2.7\right)$.

In Panel D, we see a wide variation in the amount of time spent preparing the MD\&A and $10-\mathrm{K}$, with the interquartile range varying by a magnitude of 4 to 5 times the amount of hours. Although this shows a wide variation in the amount of time, we should note that fewer firms felt comfortable responding to this question given that different divisions are involved in preparing 
these disclosures, thus making it more difficult to estimate the collective time spent accurately. In several instances, managers followed up after completing the survey to update their number to reflect additional information they collected from other divisions.

In Panel E, we describe who is involved and the relative amount of effort each manager expends in creating the MD\&A. We find that the CFO, followed by legal (internal), followed by IR (internal) are the most involved. The differences in effort are also statistically significant (CFO vs. legal: t-stat.= 2.3; legal vs. IR: t-stat.= 3.2). For 85 percent of firms ( $n=156)$, legal (internal) is in the top three managers focused on the MD\&A. IR is somewhat less common, appearing among the top three managers for 65 percent $(n=118)$ of firms. We also find the $\mathrm{CEO}$ as ranking relatively low in the relative amount of effort devoted to preparing the MD\&A; in only 10 percent of firms is the CEO the most involved, or tied for most involved manager. Thus, from the standpoint of executive leadership, the CFO should typically be viewed as the author of the document; in 62 percent of firms the CFO is the most involved manager.

Despite these average inferences which show some commonality across firms, we do find some significant variation with the board and even PR/marketing becoming heavily involved in the MD\&A creation process. In 18 firms, the $\mathrm{PR} /$ marketing department is among the top three most involved in creating the MD\&A, and for 6 firms, PR/marketing is the most involved. Of the 6 firms that rely most heavily on PR/marketing, 4 are in the software industry. For 19 firms - 10 percent of the sample-we also find that the board is among the top three most involved departments. While for the majority of firms the board and PR/marketing are largely uninvolved in MD\&A creation, we do find some firms relying on substantially different processes and departments.

Overall, we find that the finance department tends to be the dominant author of the MD\&A, rather than IR, despite the common practitioner view. We do find significant variation, however. Some firms rely on the CEO and board more heavily in drafting the MD\&A, and in some instances we even find $\mathrm{PR} /$ marketing taking a first-order role in this drafting. We also find that the timing of drafting the MD\&A varies widely. Over a third of firms begin drafting a month or more ahead of others and late preparers are associated with more frequent revisions. We further find that a significant reliance on the prior year's MD\&A with those firms starting their drafting process earlier more heavily reliant on the prior year's text. Thus, the effort, participants, and timing all vary significantly in the creation of MD\&As across firms. 


\subsection{Timing Data}

In Table 3, we provide data on when firms have compiled preliminary and final earnings numbers and when they are publicly disseminated in an earnings announcement. We find that the average amount of time, in weeks, between preliminary and final results and their dissemination is 2.8 and 1.7 weeks, respectively.

In Panel B, we compare when managers are aware of their preliminary/final earnings numbers and when they begin preparing for their earnings conference call. We find that 65 percent of firms begin preparing for the conference call before even the preliminary financial results are known for the quarter. For these firms, preparation begins, on average, two weeks before the earnings results. We also find that 80 percent of firms begin preparation for the conference call in advance of the final results being known. This evidence suggests that many firms are drafting material that is "neutral" to the financial performance of the firm.

\section{DISCLOSURE VARIATION AS A FUNCTION OF PREPARATION AND EFFORT}

In this section, we utilize our field data to better understand how differences in preparation are associated with variation in common measures of structure and tone for conference calls and MD\&As. ${ }^{15}$ In Section 5.1, we focus on the introductory remarks and Q\&A on quarterly conference calls. In Section 5.2, we focus on MD\&As.

\subsection{Conference Call Style}

The conference call contains two distinct sections, the introductory presentation section and the Q\&A section. As discussed in Section 4, we find that different processes are involved for each component of the call and thus examine the introductory and Q\&A sections separately in Tables 4 and 5, respectively.

In model 1 of Table 4, we examine the length of the introductory remarks. We find that firms that employ a script have shorter introductions. In particular, the use of a script only is

\footnotetext{
${ }^{15}$ In addition to the results included in this discussion, we tested several hypotheses relating disclosure creation to disclosure presentation that did not yield significant and/or meaningful results. In particular, for the MD\&A we examined the relationship between legal expert involvement and legal language or "uncertain" tone, executive involvement and references to management, finance expert involvement and numeric references, disclosure preparation and forward-looking references, preparation and language complexity, and whether results extend when presentation and tone outcomes are measured over the entire 10-K.
} 
associated with a 13.4 percent decrease in the length of the introduction. Prior literature (see Matsumoto, Pronk, and Roelofsen 2011) suggests that the Q\&A is the most informative portion of the call, so being more concise in the presentation can enhance the informativeness of the call. That said, we do find that firms that seek to have longer presentation portions ex ante make more extensive introductions, suggesting that some managers prefer to consume a larger portion of their call for introductory remarks (coefficient $=0.39$, p-value $<0.05) .{ }^{16}$

In models (2) and (3), we examine negative and positive language, respectively, in the introductory remarks. We find in model (2) that when PR/marketing becomes more involved in drafting the presentation of the call, the amount of negative words is significantly reduced (coefficient $=-1.32$, p-value $<0.05$ ). A one-standard-deviation increase in relative $\mathrm{PR} / \mathrm{marketing}$ involvement is associated with a nearly 7 percent decrease in the proportion of negative words in a firm's call introduction. We do not find an increase in positive language with $\mathrm{PR} / \mathrm{marketing}$ involvement in model (3), suggesting that PR/marketing seeks to avoid negative publicity during the remarks, but does not simultaneously seek to create a positive language bias.

We also find in models (2) and (3) that the greater involvement of legal counsel reduces negative language (internal and external counsel) and positive language (external counsel). The reduction of positive language is consistent with Rogers, Buskirk, and Zechman (2011), who find that more positive language is associated with shareholder litigation. Thus, external counsel tends to reduce such risks by reducing the use of positive language. In our sample, we find that a onestandard-deviation increase in the level of internal and external legal involvement is associated with a 4.3 percent and 4.5 percent decrease, respectively, in the proportion of negative words on the call introduction. A one-standard-deviation increase in external legal involvement is further associated with a 4.2 percent decrease in the proportion of positive words. Overall, we find that legal counsel reduces negative and positive language. Although negative language may be constructed by some as being more “conservative,” thereby suggesting that risk-averse attorneys would be amenable to its inclusion, negative language can also increase litigation risk (for examples, see Chapter 10 of Soltes 2016). Thus, by reducing the positive and negative language, external counsel can fulfill its role of reducing risk for firms.

\footnotetext{
${ }^{16}$ In the regression analyses, we utilize scaled effort. To compute scaled effort, we summed the total effort expended by all members (where 1 is no involvement and 6 is most involved). For each firm, we then divided the effort of the specific manager by total effort for that firm.
} 
In Table 5, we examine the Q\&A portion of the conference call. Managers who employ a more improvised style for the Q\&A (as opposed to a scripted style) answer more questions. Our analyses imply that following a more improvised style is associated with taking on approximately 10 percent more analyst questions on a given call. We also find that CEOs engage more on a call (by speaking more frequently) when questions from sell-side and buy-side analysts are collected in advance. Advance engagement with analysts increases the frequency of CEO engagement during the call by 14 percent. Thus, the style and advance preparation of calls is associated with variation in engagement on the call.

We also find that the tone on calls is influenced by differences in preparation. Executives employ the pronoun "we" less often during the Q\&A if they do not script (i.e. employ a more improvised style in) the Q\&A. The lack of "we" when speaking more extemporaneously is consistent with some scholars who have suggested that mangers may have self-serving attribution bias (see Li 2010). ${ }^{17}$ We also find that executives who prepare Q\&A responses employ more negative and less positive language during the Q\&A. This indicates that calls with scripted Q\&As employ more cautious language, but when left to speak on their own, executives spontaneously use more positive and negative language.

Overall, we find that during conference calls, several different aspects of effort and preparation are associated with variable language and style on the call. ${ }^{18}$ Most notably, we find that $\mathrm{PR} /$ marketing and legal impact language in the introductory remarks in a manner consistent with their objectives within the organization. Moreover, we find that executives who speak more extemporaneously during the Q\&A tend to answer more questions and employ more "descriptive" (i.e. positive and negative) language to describe their firms and firm performance.

\footnotetext{
${ }^{17}$ We also ran our analyses on other first-, second-, and third-person pronouns and did not find statistically significant relationships between these references and preparation.

${ }^{18}$ For the conference calls, we explored several hypotheses that did not yield meaningful or significant results, or that we could not interpret based on hypotheses from the prior literature. In particular, we analyzed the relationship between preparation and additional tonal outcomes such as use of deception and/or anxiety words, hesitancy words, and references to first-person versus second- and third-person pronouns; CEO/CFO question collection or advance preparation and the number of questions asked on the call; and whether results consistently extend when dependent variables (tone, length) are measured at the managerial level (CEO/CFO) as opposed to the call section level (presentation, Q\&A).
} 


\subsection{MD\&A Style}

In Table 6, we examine how differences in preparation and involvement are associated with variation in MD\&A characteristics. ${ }^{19}$

In model (1), we examine optimism in the MD\&A. In line with the objectives of $\mathrm{PR} /$ marketing managers, the greater involvement their departmental involvement in MD\&A preparation, the more optimistic we find the language in the MD\&A (coefficient $=1.72$, pvalue $<0.05$ ). Specifically, a one-standard-deviation increase in $\mathrm{PR} /$ marketing involvement is associated with a nearly 6 percent increase in the proportion of optimistic language in the MD\&A. We also find that when external legal counsel is more involved there is less optimistic language. One unexpected finding is that greater CEO involvement is associated with lower optimism (coefficient $=-2.31$, p-value $<0.01$ ). One potential explanation is that by expressing optimism in the MD\&A, the CEO is setting up higher expectations for the future, which can have adverse personal consequences if expectations are not met. Anticipating this, the CEO may seek to moderate expectations. For example, Schrand and Zechman (2010) find that financial misreporting often begins with an initial optimistic statement that sets the executive on a slippery slope to later misreport in line with those expectations. To the extent that executives seek to avoid being compromised in such a manner, they might seek to employ less optimistic language in their firms' statements.

In model (2), we examine MD\&A similarity on the basis of the information conveyed by modifications that firms make (e.g. Brown and Tucker 2011). We find that a one-standarddeviation increase in relative $\mathrm{PR} /$ marketing involvement is associated with an increase in the likelihood of having above-median MD\&A similarity by 0.10 (significant at 1 percent). Likewise, a one-standard-deviation increase in relative legal internal involvement is associated with an increase in the likelihood of having above-median MD\&A similarity by 0.08 (significant at 10 percent).

In models (3) and (4) we examine MD\&A complexity—as measured by FOG and BOG (following Lehavy, Li, and Merkley 2011 and Bonsall et al. 2017, respectively). Although we do not find that FOG is associated with differential effort by managers, we do find that firms that prepare their MD\&A farther in advance employ marginally less complex language. In particular,

\footnotetext{
${ }^{19}$ We find the following results generally hold when MD\&A variables are measured over the entire 10-K; however, we restrict our discussion to results using MD\&A measures since our survey questions specifically targeted MD\&A preparation practices.
} 
a one-standard-deviation increase in the number of weeks in advance the firm prepares its MD\&A is associated with a decrease in the likelihood of having above-median FOG by .13 (significant at 1\%) and above-median BOG by .07 (significant at 5\%). This suggests that advance preparation is associated with less complex, more readable MD\&A disclosures. In recent years, the SEC has placed significant attention on its "plain language” requirements by encouraging companies to use simpler language in their disclosures. To the extent that organizations begin these disclosures farther in advance, allowing greater care to be taken, we find greater alignment with the plainlanguage goal.

In summary, we find a number of ways in which differential managerial involvement is associated with differences in the style and presentation of MD\&As. In particular, when $\mathrm{PR} /$ marketing — a department not normally viewed as being involved in regulatory disclosuresbecomes more heavily involved, we find that disclosures are more optimistic, more complex, and more similar (i.e. less informative) year-over-year. As the objective of marketing departments is "selling” the firm and its products rather than unbiased communications of news, this would be consistent with marketing functions impeding transparent firm communications.

\section{CONCLUSION}

Accounting researchers have long studied firm disclosure practices. However, firms do not actually make disclosure decisions. Instead, it is individual managers within firms that make actual disclosure choices. By collecting an extensive set of field data, our investigation seeks to explore how the preparation, timing, and effort of different managers within firms manifest in disclosure practices. We find that despite the tendency of firms to benchmark with one another, there is significant heterogeneity in how managers create their MD\&A and conference call disclosures. We also show that this variation in preparation styles results in differences in the appearance of those disclosures. Specifically, changes in effort and preparation are associated with the language (e.g. optimistic words), style (e.g. complexity), and presentation of firm disclosures.

Our analysis begins to illuminate the people behind the disclosure process, but there are considerable opportunities for further research. While our field data describes how different managers create disclosures, it does not assess why these differing practices arise within firms. Understanding how managers decide to approach their disclosure preparation would deepen our 
understanding of these differences. Do they arise from legacy practices (i.e. it is what a manager's predecessor at the firm did), or is it an expression of managerial preferences (e.g. the CEO does not want to spend time on MD\&A)?

As described in the introduction, our data on managerial effort and engagement is static and represents "average” practices for managers at different firms. However, preparation is likely to vary from period to period within firms. Researchers who can collect data on this period-byperiod effort would be able to shed light on additional hypotheses that have long been subject to speculation. For instance, when bad news is impending, does the PR/marketing department become more engaged and potentially seek to obfuscate the adverse news being disclosed?

Finally, we hope our field-based approach inspires other accounting researchers to collect data from within firms to study external disclosure processes. As we found from the considerable engagement of those we asked to provide us with data, managers are willing to reveal their internal firms processes to researchers. To the extent that accounting researchers have historically relied on largely public signals, this "private" and "proprietary" data could offer new and deeper ways to explore the financial reporting process. 


\section{Figure 1: Sample Disclosure Creation Schedules}

Figure 1 depicts the earnings announcement schedules for two firms. Firm A is a middle-capitalization industrial firm. Firm B is a small capitalization technology firm. The activity describes the portion of the disclosure process that a manager is involved with. The responsibility column shows the position of the manager who is accountable for completing the activity.

\section{Panel A: Firm A Earnings Announcement Schedule}

\begin{tabular}{lll} 
Date & Activity & Responsibility \\
\hline January XX-XX & First draft press release & \\
& - script & IR \\
& - strategy section & CEO \\
- financials/guidance & GC \\
January XX-XX & Draft Q\&A, preparation of conference call & CFO \\
January XX-XX & Updating Q\&A & \\
& Listen to competitor conference calls & IR \\
& Review blast list & IR \\
Prepare press release announcing call & CFO assistant \\
Collect numbers for analysts & IR \\
January XX-XX & IR \\
January XX-XX & Issue press release & IR \\
& & \\
& Finalize all materials & IR \\
February XX-XX & Legal review & Legal \\
& Board review & Board \\
& Rehearse (as needed) & IR
\end{tabular}




\section{Panel B: Firm B Earnings Announcement Schedule}

Date

2-3 weeks before

2 weeks before

1 week before

$<7$ days before

Day of

Day after
Activity

Responsibility

Financials/messaging meeting

Monitor first call to be sure estimates are accurate

Press release on timing of conference call

First drafts of script to CFO

Share drafts with marketing and PR for Input

Comments and revisions to release and script

Finalize release and script

Develop Q\&A

Share summaries of peer calls/key points

Review materials

Manager conference call

Review transcript; share

Update
CEO, CFO, IR

IR

IR

CFO

PR

Auditors, CFO

CEO, CFO, GC

IR

IR

GC, Board

All

IR

IR 


\section{Table 1: Conference Call Field Data Summary}

Table 1 describes the conference call-related data collected from the field questionnaires. Each panel shows a question posed to firm managers and a summary of firm responses. INC stands for "incomplete" and indicates the number of respondent firms that did not provide an answer to the given question.

\section{Panel A:}

On average over the past 4 quarters, how long prior to the quarterly conference call does the draft of the management's remarks begin being drafted?

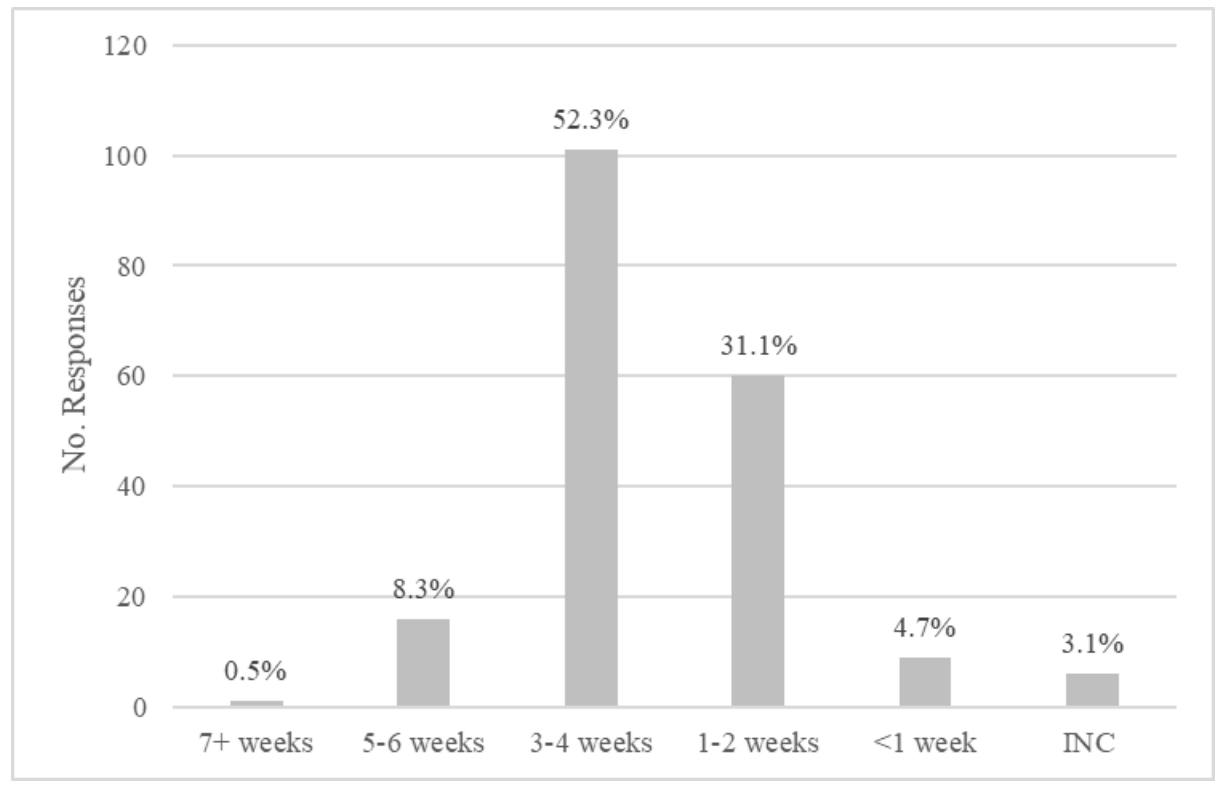

Panel B:

What types of materials, if any, are typically prepared for presentation portion of conference calls?

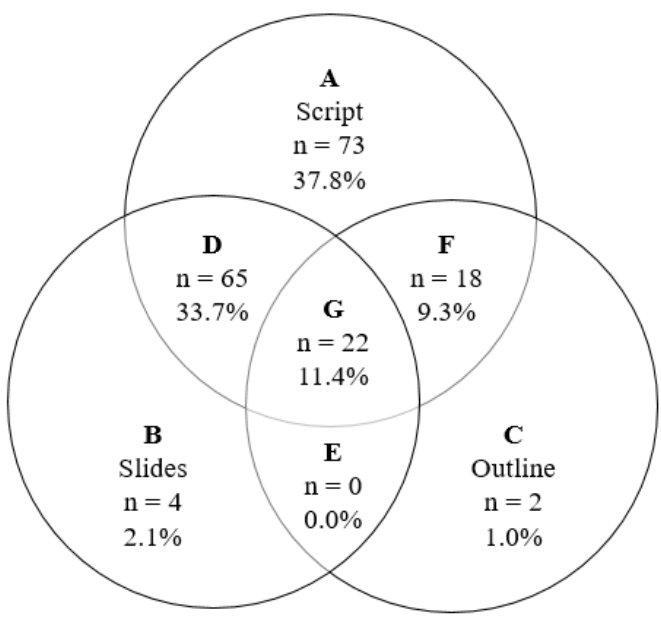

The Venn diagram displays the items_-script, slides, and outline-prepared for the meeting. Firms counted in overlapping areas of the diagram prepared more than one item. Note that 9 firms $(4.7 \%)$ declined to respond. 


\section{Panel C:}

How would you characterize your company’s preparation style for the Q\&A session?

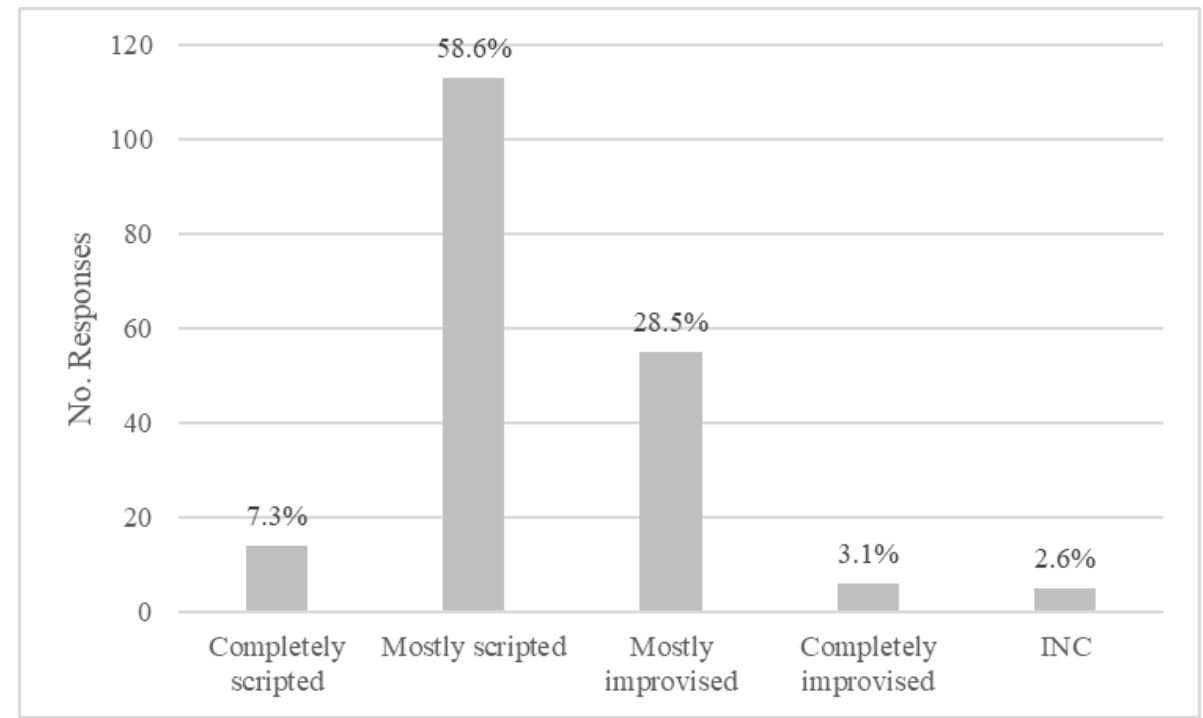

Panel D:

Does your company prepare responses to potential questions that might be raised during conference calls?

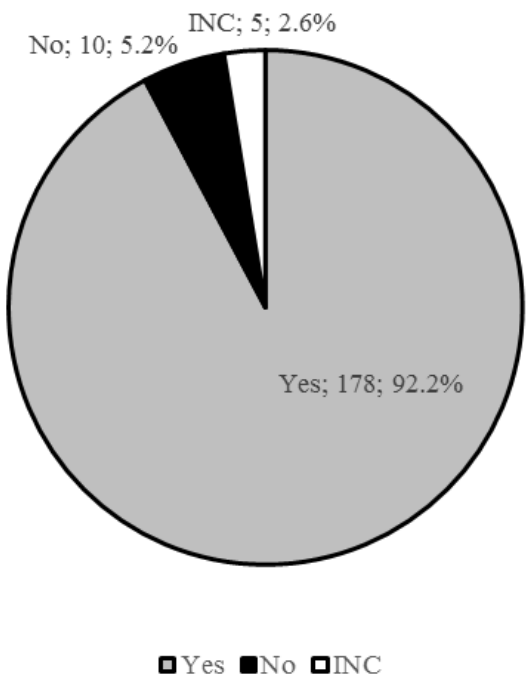




\section{Panel E:}

Does someone from the company speak with sell-side analysts or buy-side investors in advance and collect potential questions of interest?

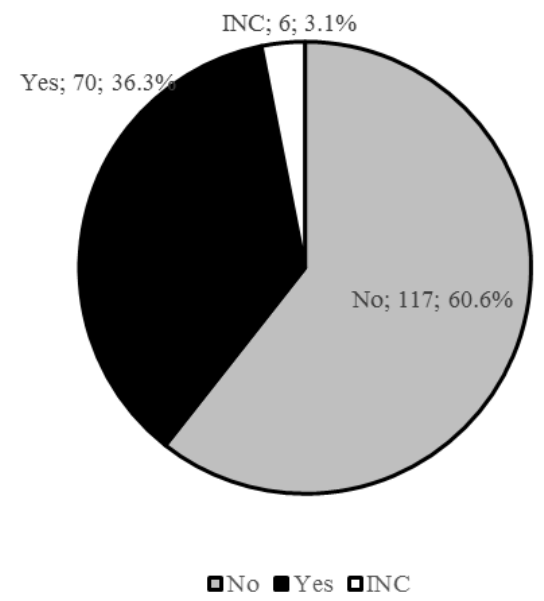

\section{Panel F:}

On average over the past 4 quarters, how long does the CEO/CFO spend preparing for the quarterly conference call? (in hours)

\begin{tabular}{lcccccc}
\hline & No. Responses & Mean & Median & Std. Dev. & Q1 & Q3 \\
\hline CEO preparation time & 181 & 9.0 & 7.5 & 9.0 & 3.0 & 10.0 \\
CFO preparation time & 177 & 15.7 & 11.0 & 17.5 & 6.0 & 20.0 \\
\hline \hline
\end{tabular}




\section{Panel G:}

How involved is each department in drafting the introductory management remarks for conference calls? Describe each department's involvement on a scale of $1=$ least involved to $5=$ most involved.

(0 means no involvement)

\begin{tabular}{ccccccccc}
\hline & No. Responses & Row & Mean & Median & Std. Dev & Q1 & Q3 & $\begin{array}{c}\text { Mean statistically } \\
\text { different from row: }\end{array}$ \\
\hline IR internal & 186 & 1 & 4.3 & 5.0 & 1.6 & 5.0 & 5.0 & $3-9$ \\
CFO & 187 & 2 & 4.1 & 4.0 & 0.9 & 4.0 & 5.0 & $3-9$ \\
CEO & 189 & 3 & 3.7 & 4.0 & 1.1 & 3.0 & 4.0 & $1-2,4-9$ \\
Legal internal & 184 & 4 & 2.3 & 2.0 & 1.4 & 1.0 & 3.0 & $1-3,5-9$ \\
PR/Marketing & 183 & 5 & 1.2 & 0.0 & 1.6 & 0.0 & 2.0 & $1-4,7-9$ \\
IR external & 174 & 6 & 1.2 & 0.0 & 1.9 & 0.0 & 2.0 & $1-4,7-9$ \\
Legal external & 185 & 7 & 0.9 & 0.0 & 1.2 & 0.0 & 1.0 & $1-6,8-9$ \\
Board & 186 & 8 & 0.6 & 0.0 & 0.9 & 0.0 & 1.0 & $1-7$ \\
External audit & 185 & 9 & 0.5 & 0.0 & 0.9 & 0.0 & 1.0 & $1-7$ \\
\hline
\end{tabular}

\section{Panel H:}

On average after an earnings conference call, how many calls from sell-side/buy-side analysts does your company take within 72 hours after the conference call?

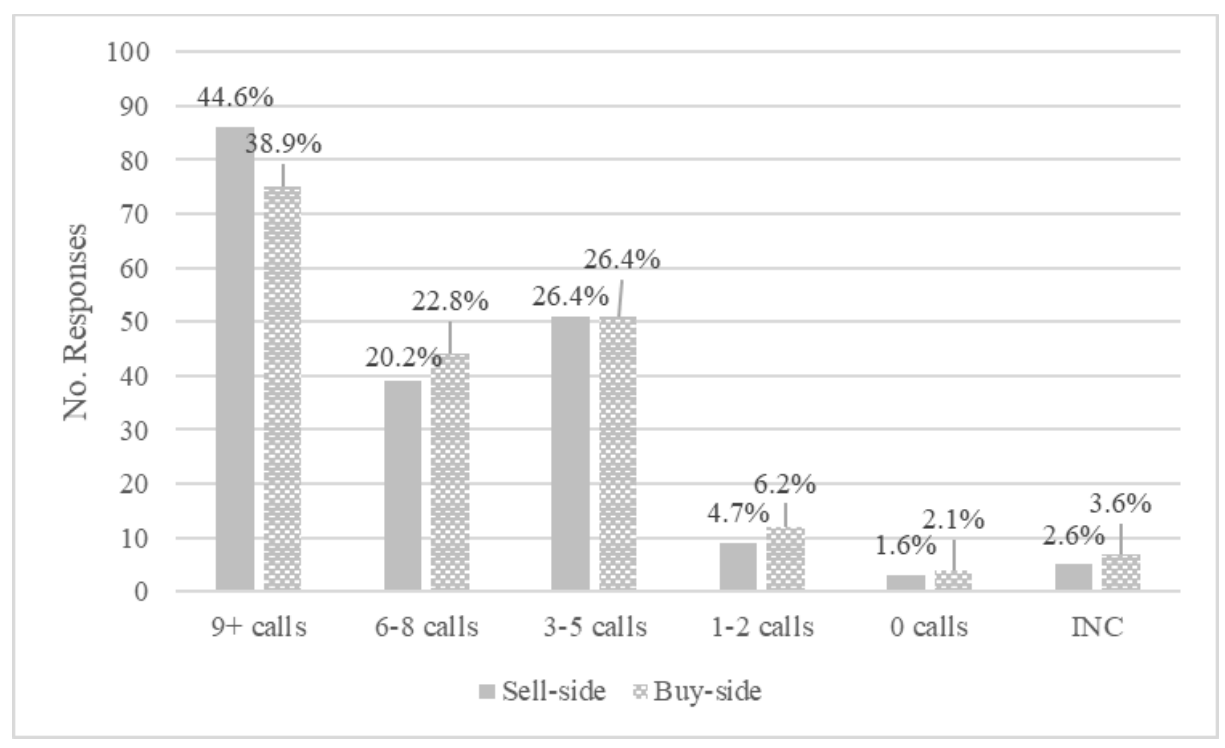




\section{Table 2: 10-K/MD\&A Field Data Summary}

Table 2 describes the 10-K and MD\&A related data collected from the field questionnaires. Each panel describes a question posed to firm managers and a summary of firm responses. INC stands for "incomplete" and indicates the number of respondent firms that did not provide an answer to the given question.

\section{Panel A:}

Which department is primarily responsible for the first draft of the MD\&A section in the Form 10-K?

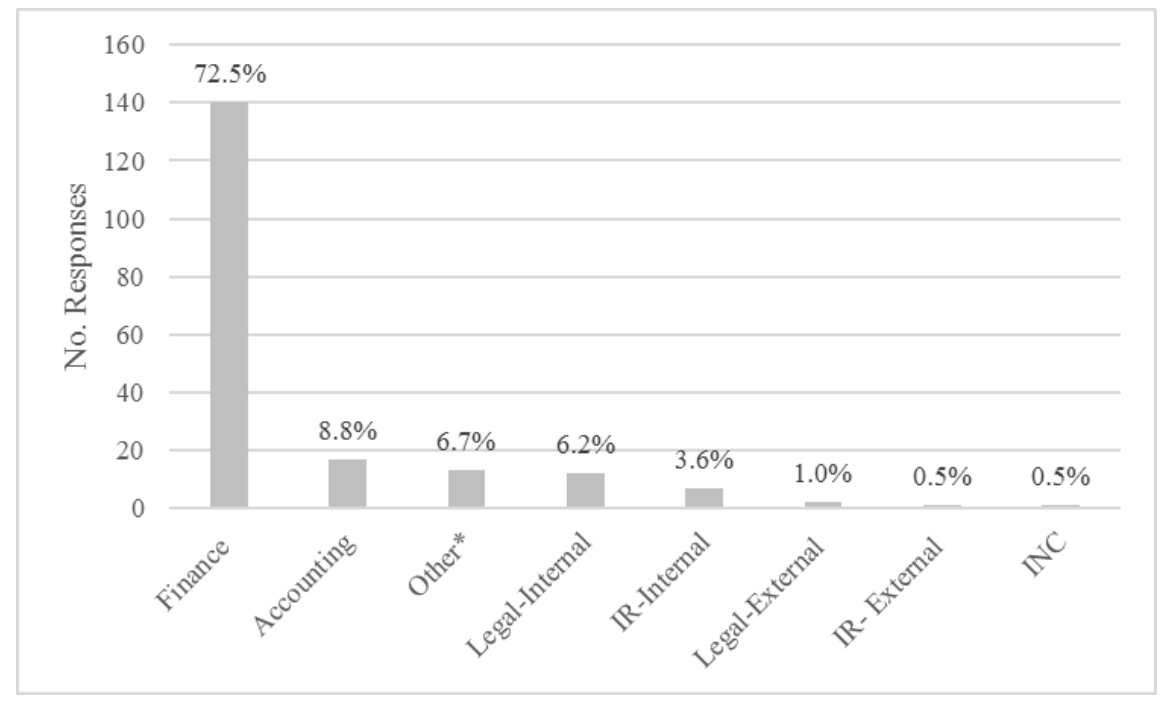

*Other includes write-in responses with one instance each of marketing, business segment leader, CEO, external reporting, FPRA, SEC, SEC reporting team, and VP business development.

\section{Panel B:}

In your most recent Form 10-K, how long prior to the filing of the Form 10-K did this individual or team begin the draft of the MD\&A section?

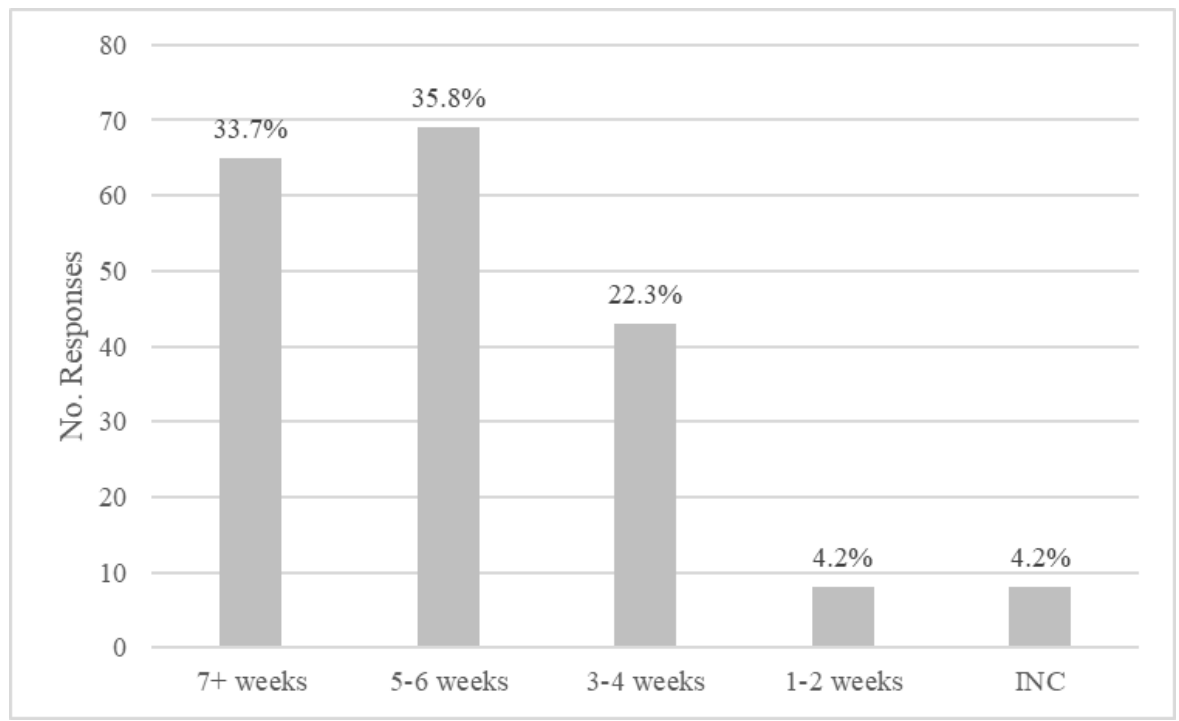




\section{Panel C:}

When creating the draft for the current year's MD\&A, to what degree does the primary author rely on the prior year's MD\&A as a template?

\begin{tabular}{lcccccc}
\hline & No. Responses & Mean & Median & Std. Dev & Q1 & Q3 \\
\hline Template reliance & 189 & 0.6 & 0.7 & 0.2 & 0.3 & 0.7 \\
\hline \hline
\end{tabular}

Reponses are scaled to between 0 and 1, where 0 is no reliance, . 33 is some reliance, .67 is strong reliance, and 1 is very strong reliance.

\section{Panel D:}

Estimate the total number of hours your company collectively takes to prepare the following disclosures:

MD\&A and 10-K

\begin{tabular}{ccccccc}
\hline & No. Responses & Mean & Median & Std. Dev & Q1 & Q3 \\
\hline MD\&A & 112 & 94.7 & 50.0 & 116.5 & 20.0 & 100.0 \\
10-K & 107 & 364.6 & 200.0 & 483.9 & 100.0 & 400.0 \\
\hline \hline
\end{tabular}

\section{Panel E:}

How involved is each department in creating the MD\&A? Describe each department's involvement on a scale of 1 = least involved to 5 = most involved. ( 0 means no involvement)

\begin{tabular}{ccccccc}
\hline \hline & No. Responses & Mean & Median & Std. Dev. & Q1 & Q3 \\
\hline CFO & 188 & 3.6 & 4.0 & 1.2 & 3.0 & 5.0 \\
Legal internal & 183 & 3.3 & 4.0 & 1.5 & 3.0 & 4.0 \\
IR internal & 182 & 2.8 & 3.0 & 1.5 & 2.0 & 4.0 \\
External audit & 182 & 2.4 & 2.0 & 1.5 & 1.0 & 3.0 \\
Legal external & 182 & 2.2 & 2.0 & 1.5 & 1.0 & 3.0 \\
CEO & 189 & 1.9 & 2.0 & 1.3 & 1.0 & 3.0 \\
Board & 181 & 1.2 & 1.0 & 1.0 & 0.0 & 2.0 \\
PR/Marketing & 179 & 0.7 & 0.0 & 1.0 & 0.0 & 1.0 \\
IR external & 169 & 0.5 & 0.0 & 1.2 & 0.0 & 0.0 \\
\hline
\end{tabular}




\section{Table 3: Timing of Financial Reports Data Summary}

Table 3 describes the data on the timing of the financial reporting process from the field questionnaires. Each panel describes a question posed to firm managers and a summary of firm responses.

\section{Panel A:}

On average over the past 4 quarters, what is the approximate time between when preliminary quarterly financial results are known to senior management and when they are publicly disseminated? (in weeks)

\begin{tabular}{lcccccc}
\hline & No. Responses & Mean & Median & Std. Dev. & Q1 & Q3 \\
\hline Preliminary results & 179 & 2.8 & 3.0 & 1.7 & 2.0 & 4.0 \\
Final results & 182 & 1.7 & 1.5 & 1.3 & 0.9 & 2.0 \\
\hline
\end{tabular}

\section{Panel B:}

\begin{tabular}{|c|c|c|c|c|c|c|c|}
\hline \multirow{2}{*}{\multicolumn{8}{|c|}{ No. Firms Tot. Responses }} \\
\hline & & & & & & & \\
\hline Call preparation time vs. knowledge of preliminary results & 172 & 172 & 0.8 & 0.5 & 2.3 & -0.5 & 2.5 \\
\hline Call preparation time vs. knowledge of final results & 175 & 175 & 2.0 & 2.5 & 2.0 & 0.5 & 3.5 \\
\hline \multicolumn{8}{|l|}{ Sub-sample of firms that prepare call before results known } \\
\hline Prepare call before preliminary results & 112 & 172 & 2.1 & 2.4 & 1.5 & 0.6 & 3.1 \\
\hline Prepare call before final results & 140 & 175 & 2.7 & 2.5 & 1.5 & 1.5 & 3.5 \\
\hline
\end{tabular}




\section{Table 4: Conference Call Presentation and Managerial Engagement}

Table 4 investigates differential managerial engagement and the introduction made on earnings conference calls. The dependent variable "Length intro (ln)" is the log of the average number of words spoken during the introduction section of the call over the firm's four earnings conference calls of 2016. The dependent variables "Negative" and "Positive" are the logs of the average percent of negative words and positive words, respectively, contained in each firm's call introduction over the firm's four earnings conference calls of 2016. Additional variables are described in Appendix 1. ***, **, * indicate statistical significance at the $1 \%$, $5 \%$, and $10 \%$ level, respectively.

\begin{tabular}{|c|c|c|c|}
\hline & (1) & (2) & (3) \\
\hline & Length Intro (In) & Negative & Positive \\
\hline \multirow[t]{2}{*}{ Market cap (In) } & $0.015^{* *}$ & -0.007 & 0.005 \\
\hline & $(0.006)$ & $(0.004)$ & $(0.003)$ \\
\hline \multirow[t]{2}{*}{ Returns } & 0.042 & 0.026 & 0.025 \\
\hline & $(0.030)$ & (0.016) & $(0.024)$ \\
\hline \multirow[t]{2}{*}{ Advance draft } & 0.019 & 0.004 & 0.009 \\
\hline & $(0.021)$ & $(0.012)$ & $(0.010)$ \\
\hline \multirow[t]{2}{*}{ Management forecast } & 0.097 & -0.053 & $0.060^{*}$ \\
\hline & $(0.074)$ & $(0.037)$ & $(0.032)$ \\
\hline \multirow[t]{2}{*}{ Prepared script only } & $-0.134 * * *$ & & \\
\hline & (0.049) & & \\
\hline \multirow[t]{2}{*}{ Percent presentation } & $0.389 * *$ & & \\
\hline & $(0.167)$ & & \\
\hline \multirow[t]{2}{*}{$\mathrm{PR} /$ marketing involvement } & & $-1.318^{* *}$ & 0.393 \\
\hline & & $(0.511)$ & $(0.418)$ \\
\hline \multirow[t]{2}{*}{ Legal (int) involvement } & & $-0.814 *$ & -0.381 \\
\hline & & $(0.469)$ & $(0.396)$ \\
\hline \multirow[t]{2}{*}{ Legal (ext) involvement } & & $-1.114^{* *}$ & $-1.021 * *$ \\
\hline & & $(0.531)$ & $(0.510)$ \\
\hline \multirow[t]{2}{*}{ CEO involvement } & & $-0.821^{*}$ & -0.189 \\
\hline & & $(0.468)$ & $(0.373)$ \\
\hline \multirow[t]{2}{*}{ CFO involvement } & & -0.444 & -0.430 \\
\hline & & $(0.581)$ & $(0.498)$ \\
\hline \multirow[t]{2}{*}{ IR (int) involvement } & & -0.476 & -0.257 \\
\hline & & $(0.360)$ & $(0.321)$ \\
\hline \multirow[t]{2}{*}{ IR (ext) involvement } & & -0.445 & 0.042 \\
\hline & & $(0.406)$ & $(0.352)$ \\
\hline \multirow[t]{2}{*}{ Length intro (In) } & & -0.006 & 0.048 \\
\hline & & $(0.046)$ & $(0.038)$ \\
\hline \multirow[t]{2}{*}{ Constant } & $7.539 * * *$ & $1.404^{* * *}$ & $0.854^{* *}$ \\
\hline & $(0.111)$ & $(0.476)$ & $(0.417)$ \\
\hline $\mathrm{N}$ & 179 & 187 & 187 \\
\hline $\mathrm{R} 2$ & 0.12 & 0.08 & 0.18 \\
\hline
\end{tabular}




\section{Table 5: Conference Call Q\&A and Managerial Engagement}

Table 5 investigates differential managerial engagement and the Q\&A portion of earnings conference calls. The dependent variable "Questions (ln)" is the log of the average number of questions coming from analysts over the firm's four earnings conference calls of 2016. The dependent variable "Number of times CEO speaks” is the log of the average times the CEO speaks during each firm's conference call over the firm's four earnings conference calls of 2016. The dependent variable "We" is the log of the average number of references to first-person plural pronouns ("we”) over the firm's four earnings conference calls of 2016. The dependent variables "Negative" and "Positive" are the logs of the average percent of negative and positive words respectively contained in each firm's Q\&A section over the firm' four earnings conference calls of 2016. Additional variables are described in Appendix 1. ***, **, * indicate statistical significance at the $1 \%, 5 \%$, and $10 \%$ level, respectively.

\begin{tabular}{|c|c|c|c|c|c|}
\hline & $\begin{array}{c}\text { (1) } \\
\text { Questions (In) }\end{array}$ & $\begin{array}{c}\mathbf{( 2 )} \\
\text { Number of times } \\
\text { CEO speaks } \\
\end{array}$ & $\begin{array}{l}\text { (3) } \\
\text { We }\end{array}$ & $\begin{array}{c}\text { (4) } \\
\text { Negative }\end{array}$ & $\begin{array}{c}\text { (5) } \\
\text { Positive }\end{array}$ \\
\hline Market cap (In) & $\begin{array}{l}-0.004 \\
(0.008)\end{array}$ & $\begin{array}{l}-0.001 \\
(0.012)\end{array}$ & $\begin{array}{l}0.005^{* *} \\
(0.002)\end{array}$ & $\begin{array}{l}0.004^{* *} \\
(0.002)\end{array}$ & $\begin{array}{c}0.003 \\
(0.004)\end{array}$ \\
\hline Returns & $\begin{array}{l}0.104^{* *} \\
(0.041)\end{array}$ & $\begin{array}{c}0.174 * * * \\
(0.040)\end{array}$ & $\begin{array}{l}-0.008 \\
(0.013)\end{array}$ & $\begin{array}{c}0.004 \\
(0.008)\end{array}$ & $\begin{array}{l}-0.006 \\
(0.020)\end{array}$ \\
\hline Advance questions & $\begin{array}{l}-0.033 \\
(0.052)\end{array}$ & $\begin{array}{l}0.144^{*} \\
(0.077)\end{array}$ & $\begin{array}{l}-0.017 \\
(0.013)\end{array}$ & $\begin{array}{l}-0.014 \\
(0.013)\end{array}$ & $\begin{array}{l}-0.027 \\
(0.025)\end{array}$ \\
\hline Management forecast & $\begin{array}{l}0.170 * * \\
(0.069)\end{array}$ & $\begin{array}{c}0.097 \\
(0.069)\end{array}$ & $\begin{array}{l}-0.024 \\
(0.019)\end{array}$ & $\begin{array}{l}-0.004 \\
(0.018)\end{array}$ & $\begin{array}{c}0.016 \\
(0.028)\end{array}$ \\
\hline No prepared responses & $\begin{array}{l}-0.078 \\
(0.066)\end{array}$ & $\begin{array}{l}-0.198 \\
(0.129)\end{array}$ & $\begin{array}{c}0.001 \\
(0.025)\end{array}$ & $\begin{array}{c}0.063 * * * \\
(0.018)\end{array}$ & $\begin{array}{c}-0.133^{* * *} \\
(0.046)\end{array}$ \\
\hline Improvised style & $\begin{array}{l}0.103 * * \\
(0.047)\end{array}$ & $\begin{array}{c}0.015 \\
(0.061)\end{array}$ & $\begin{array}{c}-0.027^{* *} \\
(0.014)\end{array}$ & $\begin{array}{l}-0.007 \\
(0.014)\end{array}$ & $\begin{array}{l}-0.007 \\
(0.025)\end{array}$ \\
\hline Analyst coverage & $\begin{array}{c}0.033^{* * *} \\
(0.012)\end{array}$ & $\begin{array}{c}0.025 \\
(0.016)\end{array}$ & $\begin{array}{c}-0.008^{* *} \\
(0.003)\end{array}$ & $\begin{array}{l}-0.001 \\
(0.003)\end{array}$ & $\begin{array}{c}0.003 \\
(0.005)\end{array}$ \\
\hline Length $Q \& A(I n)$ & $\begin{array}{c}0.487^{* * *} \\
(0.050)\end{array}$ & & $\begin{array}{c}0.004 \\
(0.014)\end{array}$ & $\begin{array}{c}0.014 \\
(0.014)\end{array}$ & $\begin{array}{l}0.055^{* *} \\
(0.028)\end{array}$ \\
\hline Length CEO (In) & & $\begin{array}{c}0.365 * * * \\
(0.094)\end{array}$ & & & \\
\hline Constant & $\begin{array}{c}-0.980^{* * *} \\
(0.326) \\
\end{array}$ & $\begin{array}{l}-0.219 \\
(0.502) \\
\end{array}$ & $\begin{array}{c}1.907 * * * \\
(0.098) \\
\end{array}$ & $\begin{array}{l}0.218^{* *} \\
(0.089) \\
\end{array}$ & $\begin{array}{l}0.467^{* *} \\
(0.186) \\
\end{array}$ \\
\hline $\mathrm{N}$ & 187 & 187 & 187 & 187 & 187 \\
\hline R2 & 0.64 & 0.57 & 0.12 & 0.07 & 0.12 \\
\hline
\end{tabular}




\section{Table 6: MD\&A Characteristics and Managerial Engagement}

Table 6 investigates managerial preparation and the style and presentation of the MD\&A. Model (1) uses an OLS specification, and models (2)-(4) use probit specifications. The dependent variable "Optimism" is the log of average optimism score for each firm's MD\&A across 2015 and 2016, calculated following Henry (2008). The dependent variable "High MD\&A similarity" is an indicator variable equal to one if the firm's similarity score is above-median for all firms, where similarity is calculated as one minus the average "Rawscore" for each firm. ("Rawscore" is a measure of MD\&A changes or modifications year over year calculated following Brown and Tucker 2011). The dependent variables "High MD\&A FOG Index" and "High MD\&A BOG Index" are indicator variables equal to one if the firm's average readability index score for 2015 and 2016 MD\&A is above median across all firms. FOG is calculated following Lehavy, Li, and Merkley (2011) and BOG follows Bonsall, Leone, and Miller (2017). Additional variables are described in Appendix 1. ***, **, * indicate statistical significance at the $1 \%, 5 \%$, and $10 \%$ level, respectively.

\begin{tabular}{|c|c|c|c|c|}
\hline & $\begin{array}{c}\text { (1) } \\
\text { Optimism }\end{array}$ & $\begin{array}{c}\text { (2) } \\
\text { High MD\&A } \\
\text { similarity }\end{array}$ & $\begin{array}{c}\text { (3) } \\
\text { High MD\&A } \\
\text { FOG Index }\end{array}$ & $\begin{array}{c}\text { (4) } \\
\text { High MD\&A } \\
\text { BOG Index }\end{array}$ \\
\hline Market cap (In) & $\begin{array}{c}0.009 \\
(0.008)\end{array}$ & $\begin{array}{l}0.056^{*} \\
(0.031)\end{array}$ & $\begin{array}{l}-0.002 \\
(0.031)\end{array}$ & $\begin{array}{l}-0.021 \\
(0.030)\end{array}$ \\
\hline Returns & $\begin{array}{c}-0.061^{* *} \\
(0.028)\end{array}$ & $\begin{array}{c}0.131 \\
(0.190)\end{array}$ & $\begin{array}{l}-0.236 \\
(0.194)\end{array}$ & $\begin{array}{l}-0.016 \\
(0.170)\end{array}$ \\
\hline Management forecast & $\begin{array}{c}0.044 \\
(0.062)\end{array}$ & $\begin{array}{l}-0.136 \\
(0.292)\end{array}$ & $\begin{array}{c}0.466 \\
(0.304)\end{array}$ & $\begin{array}{c}0.199 \\
(0.282)\end{array}$ \\
\hline Length MD\&A (In) & $\begin{array}{c}-0.062^{* * *} \\
(0.024)\end{array}$ & $\begin{array}{c}0.826 * * * \\
(0.204)\end{array}$ & $\begin{array}{c}1.429 * * * \\
(0.239)\end{array}$ & $\begin{array}{c}0.060 \\
(0.136)\end{array}$ \\
\hline MD\&A advance preparation & $\begin{array}{c}0.038 * * * \\
(0.013)\end{array}$ & $\begin{array}{c}0.036 \\
(0.059)\end{array}$ & $\begin{array}{c}-0.267^{* * *} \\
(0.070)\end{array}$ & $\begin{array}{l}-0.112^{*} \\
(0.058)\end{array}$ \\
\hline $\mathrm{PR} /$ marketing involvement & $\begin{array}{l}1.717^{* *} \\
(0.699)\end{array}$ & $\begin{array}{l}8.743 * * \\
(3.556)\end{array}$ & $\begin{array}{c}3.992 \\
(3.471)\end{array}$ & $\begin{array}{c}2.864 \\
(3.112)\end{array}$ \\
\hline IR (int) involvement & $\begin{array}{c}0.049 \\
(0.399)\end{array}$ & $\begin{array}{l}-2.906 \\
(1.791)\end{array}$ & $\begin{array}{l}4.227 * * \\
(1.980)\end{array}$ & $\begin{array}{c}1.966 \\
(1.723)\end{array}$ \\
\hline IR (ext) involvement & $\begin{array}{c}-1.430 * * \\
(0.716)\end{array}$ & $\begin{array}{l}-1.648 \\
(2.818)\end{array}$ & $\begin{array}{c}-9.036 * * \\
(3.796)\end{array}$ & $\begin{array}{l}-3.458 \\
(2.923)\end{array}$ \\
\hline Legal (int) involvement & $\begin{array}{l}-0.205 \\
(0.457)\end{array}$ & $\begin{array}{l}4.089 * \\
(2.404)\end{array}$ & $\begin{array}{l}5.435 * * \\
(2.712)\end{array}$ & $\begin{array}{l}4.720 * * \\
(2.198)\end{array}$ \\
\hline Legal (ext) advisory & $\begin{array}{l}-0.108^{*} \\
(0.059)\end{array}$ & $\begin{array}{l}-0.115 \\
(0.262)\end{array}$ & $\begin{array}{c}0.021 \\
(0.305)\end{array}$ & $\begin{array}{l}-0.194 \\
(0.267)\end{array}$ \\
\hline CEO involvement & $\begin{array}{c}-2.305^{* * *} \\
(0.595)\end{array}$ & $\begin{array}{l}-2.629 \\
(2.837)\end{array}$ & $\begin{array}{c}3.536 \\
(2.906)\end{array}$ & $\begin{array}{l}-1.127 \\
(2.549)\end{array}$ \\
\hline CFO involvement & $\begin{array}{l}-0.103 \\
(0.541)\end{array}$ & $\begin{array}{l}-0.544 \\
(2.602)\end{array}$ & $\begin{array}{l}-0.987 \\
(2.676)\end{array}$ & $\begin{array}{l}-1.892 \\
(2.680)\end{array}$ \\
\hline Revisions & $\begin{array}{l}0.015^{*} \\
(0.008)\end{array}$ & $\begin{array}{c}0.032 \\
(0.033)\end{array}$ & $\begin{array}{c}0.023 \\
(0.035)\end{array}$ & $\begin{array}{l}-0.042 \\
(0.031)\end{array}$ \\
\hline Constant & $\begin{array}{c}0.982 * * * \\
(0.315)\end{array}$ & $\begin{array}{c}-8.549 * * * \\
(2.241)\end{array}$ & $\begin{array}{c}-13.549 * * * \\
(2.676)\end{array}$ & $\begin{array}{l}-0.099 \\
(1.741)\end{array}$ \\
\hline $\mathrm{N}$ & 173 & 173 & 173 & 173 \\
\hline $\mathrm{R} 2$ & 0.15 & 0.17 & 0.29 & 0.09 \\
\hline
\end{tabular}




\section{References}

Bamber, L. S., J. X. Jiang, and I. Y. Wang. 2010. What's my style? The influence of top managers on voluntary corporate financial disclosure. The Accounting Review 85 (4): 1131-1162.

Bandiera, O., S. Hansen, A. Prat, and R. Sadun. 2017. CEO Behavior and Firm Performance. Harvard Business School Working Paper.

Bloom, N., R., Lemons, R. Sadun, D. Scur, and J. Van Reenen. 2016. International Data on Measuring Management Practices. American Economic Review 106 (5): 152-156.

Bloomfield, R. 2012. A Pragmatic Approach to More Efficient Corporate Disclosure. Accounting Horizons 26 (2): 357-370.

Bloomfield, R., M. Nelson, and E. Soltes. 2016. Gathering Data for Archival, Field, Survey, and Experimental Accounting Research. Journal of Accounting Research 54 (2): 341-395.

Bonsall, S., A. Leone, B. Miller, and K. Rennekamp. 2017. A plain English measure of reporting financial reporting readability. Journal of Accounting and Economics 63 (2-3): 329-357.

Bozanic, Z., P. Choudhary, and K. J. Merkley. 2016. Securities law expertise and corporate disclosure. Available at: https://papers.ssrn.com/sol3/papers.cfm?abstract_id=2662096.

Brown, L. D., A.C. Call, M.B. Clement, and N.Y. Sharp. 2015. Inside the "black box” of sellside financial analysts. Journal of Accounting Research 53 (1): 1-47.

Brown, L. D., A.C. Call, M.B. Clement, and N.Y. Sharp. 2018. Managing the Narrative: Investor Relations Officers and Corporate Disclosures. Journal of Accounting and Economics (forthcoming).

Brown, S. V., and J. W. Tucker. 2011. Large-sample evidence on firms’ year-over-year MD\&A modifications. Journal of Accounting Research 49 (2): 309-346.

Bushee, B. J., I. D. Gow, and D. J. Taylor. 2018. Linguistic complexity in firm disclosures: obfuscation or information? Journal of Accounting Research 56 (1): 85-121.

Cohen, L., C. Malloy, and Q. Nguyen. 2016. Lazy prices. Harvard Business School Working Paper.

Dichev, I. D., J. Graham, C. Harvey, and S. Rajgopal. 2013. Earnings quality: Evidence from the field. Journal of Accounting and Economics 56 (2-3): 1-33.

Ge, W., D. Matsumoto, and J. Zhang. 2011. Do CFOs Have Style? An Empirical Investigation of the Effect of Individual CFOs on Accounting Practices. Contemporary Accounting Research 28 (4): 1141-1179.

Graham, J., C. Harvey, and M. Puri. 2016. A corporate beauty contest. Management Science 63 (9): 3044-3056. 
Graham, J., C. Harvey, and S. Rajgopal. 2005. The Economic Implication of Corporate Financial Reporting. Journal of Accounting and Economics 40: 3-73.

Henry, E. 2008. Are investors influenced by how earnings press releases are written? Journal of Business Communication 45 (4): 363-407.

Hobson, J. L., W. J. Mayew, and M. Venkatachalam. 2012. Analyzing speech to detect financial misreporting. Journal of Accounting Research 51 (2): 349-392.

Hollander, S., M. Pronk, and E. Roelofsen. 2010. Does silence speak? An empirical analysis of disclosure choices during conference calls. Journal of Accounting Research 48 (3): 531563.

Hopkins, J. J., E. L. Maydew, and M. Venkatachalam. 2015. Corporate general counsel and financial reporting quality. Management Science 61 (1): 129-145.

J.P. Morgan. 2017. IR Best Practices Guide. Available at: https://www.adr.com/Content/Documents/2017_IR_Best_Practices.pdf.

Kahneman, D. 2003. Maps of bounded rationality: Psychology for behavioral economics. American Economic Review 93 (5): 1449-1475.

Kearney, C. and S. Liu. 2014. Textual sentiment in finance: a survey of methods and models. International Review of Financial Analysis 33: 171-185.

Larker, D. F., and A. A. Zakolyukina. 2012. Detecting deceptive discussions in conference calls. Journal of Accounting Research 50 (2): 495-540.

Lee, J. 2016. Can investors detect managers' lack of spontaneity? Adherence to predetermined scripts during earnings conference calls. The Accounting Review 91 (1): 229-250.

Lehavy, R., F. Li, and K. Merkley. 2011. The effect of annual report readability on analyst following and the properties of their earnings forecasts. The Accounting Review 86 (3): 1087-1115.

Li, F. 2008. Annual report readability, current earnings, and earnings persistence. Journal of Accounting and Economics 45 (2-3): 221-247.

Li, F. 2010. Textual analysis of corporate disclosures: a survey of the literature. Journal of Accounting Literature 29: 143-165.

Li, F., M. Minnis, V. Nagar, and M. Rajan. 2014. Knowledge, compensation, and firm value: an empirical analysis of firm communication. Journal of Accounting and Economics 58: 96116.

Loughran, T., and B. McDonald. 2011. When is a liability not a liability? Textual analysis, dictionaries, and 10-Ks. The Journal of Finance 66 (1): 35-65.

Loughran, Tim, and B. McDonald. 2015. The use of word lists in textual analysis. Journal of Behavioral Finance 16 (1): 1-11. 
Loughran, T., and B. McDonald. 2016. Textual analysis in accounting and finance: a survey. Journal of Accounting Research 54 (4): 1187-1230.

Matsumoto, D., M. Pronk, and E. Roelofsen. 2011. What makes conference calls useful? The information content of managers' presentations and analysts' discussion sessions. The Accounting Review 86 (4): 1283-1414.

Mayew, W. J., and M. Venkatachalam. 2012. The power of voice: managerial affective states and future firm performance. The Journal of Finance 67 (1): 1-43.

Park, J., and E. Soltes. 2018. What do investors ask managers privately? Harvard Business School Working Paper. Available at https://ssrn.com/abstract=3087369.

Porter, M., and N. Nohria. 2018. How CEOs Manage Time. Harvard Business Review. Available at: https://hbr.org/2018/07/the-leaders-calendar.

Rogers, J. L., and A. V. Buskirk. 2009. Shareholder litigation and changes in disclosure behavior. Journal of Accounting and Economics 47 (1-2): 136-156.

Rogers, J. L., A. V. Buskirk, and S. L. C. Zechman. 2011. Disclosure tone and shareholder litigation. The Accounting Review 86 (6): 2155-2183.

Schrand, C.M, and S. L.C. Zechman. 2012. Executive overconfidence and the slippery slope to financial misreporting. Journal of Accounting and Economics 53 (1-2): 311-329.

Simons, Robert. 2010. Accountability and Control as Catalysts for Strategic Exploration and Exploitation: Field Study Results. Harvard Business School Working Paper.

Solomon, D. 2012. Selective Publicity and Stock Prices. Journal of Finance 67 (2): 599-638.

Soltes, E. 2014. Incorporating field data into archival research. Journal of Accounting Research 52 (2): 521-540.

Soltes, E. 2016. Why They Do It: Inside the Mind of the White-Collar Criminal. New York: PublicAffairs.

Walsh, A. 2017. Financial Guidance on the Rise. IR Update: 16-20. 
Controls

Market cap (In)

Returns

Management forecast

\section{$\underline{M D A}$}

Involvement

$\mathrm{PR} /$ marketing, Legal (ext),

Legal (int)]

Legal (ext) advisory

Revisions

Length M\&DA (In)

High MD\&A FOG

High MD\&A BOG

High MD\&A similarity

Optimism
[CEO, CFO, IR (ext), IR(int),

\section{Appendix 1 (Variable Summary)}

Log of market capitalization, where market capitalization is calculated by multiplying share price (Compustat item PRCC_C) by number of common stock shares outstanding at end of year (Compustat item: CSHO).

Market-adjusted returns equal the total cumulative return for each firm for the calendar year 2016 (calculated by compounding monthly returns from the CRSP monthly data file, CRSP item: ret) less the equal-weighted cumulative return (calculated by compounding monthly returns from the CRSP monthly data file, CRSP item: ewretd) over the same period.

Management forecast is an indicator variable for whether the firm issued management forecasts in 2016

Relative involvement is measured by taking the respondent's involvolvement score for this position and dividing it by the total sum involvement score that respondent gave to all managers for this question. In other words, it is the percentage of the total involvement score that can be attributed to this position's involvement. Scores range between 0-1. Relative involvement is calculated separately using the same process for survey questions related to: MDA involvement (survey question \#5), call draft involvement (survey question \#18), and transparency involvement (survey question \#24).

Indicator variable equals one if the firm utilized an external legal counsel for routine purposes, non-routine purposes, or both routine and non-routine purposes.

Variable equals the number of substantive revisions the MD\&A underwent before publication (survey question \#6). Since survey respondents were asked to select a range of revisions, we interpret survey responses at the average of the response range. For example, if a firm answered that they underwent "3-5" revisions, the "Revisions" variable would take a value of 4 .

Log of the average number of words included in the firm's MD\&A from their 2015 and 2016 10-K.

Variable equals the number of weeks the firm began drafting the MD\&A section of their 10-K in advance of filing their 10-K (survey question \#2). Since survey respondents were asked to select a range of weeks of advance

MD\&A advance preprepartion preparation, we interpret survey responses at the average of the response range. For example, if a firm answered that started drafting their MD\&A "3-4 weeks" in advance, then "MD\&A Advance Preparation" would take a value of 3.5 .

High MD\&A FOG is an indicator variable for whether the firm's FOG score is above the median score across all firms. High FOG scores suggest that a text is more complex or less readable. FOG is calculated using the following formula: (MDA_mean_wps+MDA_mean_sixltr) *.4. Where MDA_mean_wps is the average words per sentence across MD\&A for each firm, and MDA_mean_sixltr is the average \% of words longer than 6 letters (more than two syllables) across MD\&A for each firm. The general formula FOG score = (average words per sentence + percent of complex words) $x$ .4, as described in Lehavy, Li, and Merkley (2011).

High MD\&A BOG is an indicator variable for whether the firm's BOG score is above the median across all firms. High BOG scores suggest that a text is more complex or less readable. BOG represents the sum of three main textual attributes: readability issues related to sentence length, English style and word difficulty, and vocabulary complexity. This paper follows the formula and methodology for calculating BOG presented in Bonsall, Leone, and Miller (2017), 333-334.

MD\&A similarity is an indicator variable equal to one if the firm's similarity score is above-median for all firms, where similarity is calculated as one minus the average "Rawscore" for each firm. "Rawscore" is a measure of MD\&A changes or modifications year over year calculated using the vector cosine similarity per Brown and Tucker (2011). VSM converts each document into a vector of $n$ length (where $n$ represents the number of unique words in that document) with vector values corresponding to the frequencies of each unique word in that document. Following Brown and Tucker (2011) word frequencies are calculater after removing stop words and after applying the Porter stemming alogrithm. The term frequencies are then weighted by their inverse document frequency. The more different two documents are, the larger the angle should be between the two documents' respective vectors. Rawscore captures this level of difference or changes between two documents.

Log of average optimism score for each firm's MD\&A across 2015 and 2016. The optimism score is calculated following Rogers, Buskirk, and Zechman (2011) which takes the sum of positive word components less the sum of negative word components divided by the total word count, where positive and negative words are defined by Henry (2008) (Figure 1). Positive words include terms such as "positive," "success," and "accomplish." Negative words include terms such as "negative," "fail," and "weak." 
Prepared script only

No prepared responses

Percent presentation

Length Intro (In)

Advance questions

Improvised style

Analyst coverage

Length QA (In)

Length CEO (In)

Negative (Intro)

Positive (Intro)

Questions (In)

We (QA)

Negative (QA)

Positive (QA)
Advance draft

Indicator equals one if the firm prepared only a script for the conference call as opposed to a script plus supplemental materials (outline or slides) (survey question \#14).

Indicator equals one if the firm did not prepare responses to potential questions that might be raised during the conference call (survey question \#15).

Variable equals the number of weeks the firm began drafting their management's remarks prior to the quarterly conference call (survey question \#12). Since survey respondents were asked to select a range of weeks of advance preparation, we interpret survey responses at the average of the response range. For example, if a firm answered that started drafting their remarks "3-4 weeks" in advance, then "Advance draft" would take a value of 3.5

Percent of the call the firm seeks to allocate for the management presentation (survey question \#20). Since survey respondents were asked to select a range of call proportions allocated to presentation, we interpret survey responses at the average of the response range. For example, if a firm answered that they seek to allocate "26-50\%" of their call to the presentation, then "Percent presentation" would take a value of .38.

Log of the average number of words spoken during the introduction section of the call over the firm's four earnings conference calls of 2016 .

Indicator equals one if someone from the company speaks with sell-side analysts or buy-side investors in advance and collects potential questions of interest (survey question \#13).

Indicator equals one if the firm characterizes its preparation style for the Q\&A session as "completely improvised" or "mostly improvised" (survey question \#19). (On the other hand, the indicator equals zero if the preparation style was reported as "mostly scripted" or "completely scripted").

Number of sell-side analysts that covered the firm on average over the prior year (survey question \#23). Since survey respondents were asked to select a range of analyst coverage, we interpret survey responses at the average of the response range. For example, if a firm answered that they had on average " $3-5$ " sell-side analysts covering their firm, then "Analyst coverage" would take a value of 4.

Log of the average number of words spoken during the Q\&A section of the call over the firm's four earnings conference calls of 2016.

Log of the average number of words spoken by the CEO during the Q\&A section of the call over the firm's four earnings conference calls of 2016.

Log of the average percent of negative words contained in each firm's call introduction over the firm's four earnings conference calls of 2016. Negative words are derived from the negative sentiment word list described by Loughran and McDonald (2011) and Loughran and McDonald (2015). These words include terms such as "abandon,"

"depleted," and "incorrect."

Log of the average percent of positive words contained in each firm's call introduction over the firm's four earnings conference calls of 2016. Positive words are derived from the positive sentiment word list described by Loughran and McDonald (2011) and Loughran and McDonald (2015). These words include terms such as "abundance," "beneficial," and "enhancement."

Log of the average number of questions coming from analysts over the firm's four earnings conference calls of 2016.

Log of the average number of references to first-person plural pronouns ("we") over the firm's four earnings conference calls of 2016

Log of the average percent of negative words contained in each firm's Q\&A section over the firm's four earnings conference calls of 2016. Negative words are derived from the negative sentiment word list described by Loughran and McDonald (2011) and Loughran and McDonald (2015). These words include terms such as "abandon," "depleted," and "incorrect."

Log of the average percent of positive words contained in each firm's Q\&A section over the firm's four earnings conference calls of 2016. Positive words are derived from the positive sentiment word list described by Loughran and McDonald (2011) and Loughran and McDonald (2015). These words include terms such as "abundance," "achieves," and "advancement."

Number of times CEO speaks Log of the average times the CEO speaks during each firm's conference call over the firm's four earnings conference calls of 2016. 


\section{Appendix 2 (Sample Selection)}

The following panels detail our sample selection as described in Section 3, as well as a univariate comparison between the Compustat firms $(\mathrm{N}=1,406)$, selected sample firms $(\mathrm{N}=500)$, and respondent sample firms $(\mathrm{N}=193)$.

Panel A: Sample selection

\begin{tabular}{lc} 
& No. Firms \\
\hline Compustat and CRSP public firms based in U.S. & 3,691 \\
Firms with four quarterly conference calls in 2016 & 1,406 \\
Initial random sample from market capitalization quartiles & 500 \\
Subsample: firms with valid IRO addresses & 422 \\
Subsample: firms without valid IRO addresses* & 78 \\
\hline Final random sample from market capitalization quartiles & 500 \\
Survey respondents & 193 \\
\hline \hline & \\
*78 firms from the initial sample of 500 firms did not have valid IRO \\
addresses. These firms were replaced by random reselection from \\
their respective market capitalization quartiles, resulting in a final \\
sample of 500 firms with valid IRO addresses.
\end{tabular}

Panel B: Univariate comparison of firm characteristics

\begin{tabular}{|c|c|c|c|c|c|c|}
\hline & $N$ & Mean & Median & Std. Dev. & t-stat. & $x^{2}$ \\
\hline \multicolumn{7}{|l|}{ Market capitalization } \\
\hline Compustat firms & 1,406 & $2,752,904.3$ & $3,109.4$ & $20,170,267.0$ & & \\
\hline Survey sample firms & 500 & $2,125,881.6$ & $3,115.1$ & $9,837,146.6$ & 0.9 & 0.0 \\
\hline Survey respondent firms & 193 & $1,571,418.0$ & $3,248.9$ & $5,963,078.0$ & 0.9 & 0.3 \\
\hline \multicolumn{7}{|l|}{$\underline{\text { Returns }}$} \\
\hline Compustat firms & 1,406 & 0.005 & -0.007 & 0.372 & & \\
\hline Survey sample firms & 500 & -0.004 & -0.014 & 0.369 & 0.6 & 2.1 \\
\hline Survey respondent firms & 193 & 0.032 & -0.009 & 0.522 & 1.3 & 2.2 \\
\hline \multicolumn{7}{|l|}{ Analyst following } \\
\hline Compustat firms & 1,406 & 10.9 & 8.5 & 8.6 & & \\
\hline Survey sample firms & 500 & 11.5 & 9.0 & 8.4 & $-1.9 *$ & $4.0^{* *}$ \\
\hline Survey respondent firms & 188 & 7.8 & 10.0 & 2.8 & -1.4 & 2.6 \\
\hline
\end{tabular}

The t-statistics in the table above test the null hypothesis that the difference in means between Compustat firms and sample firms and between Compustat firms and respondent firms, respectively, are zero. The chi-squared statistics test the null hypothesis that the difference in medians between Compustat firms and sample firms and between Compustat firms and respondent firms, respectively, are zero. We find some significant differences between the survey sample and Compustat firms in terms of analyst following, but this disappears when we consider our final sample of survey respondents. ***, **, * indicate statistical significance at the $1 \%, 5 \%$, and $10 \%$ level, respectively. 
Panel C: Comparison of sample industry distributions

\begin{tabular}{c|cc|ccc|ccc}
\hline Fama-French 17 Industry & \multicolumn{2}{|c|}{ Compustat firms } & \multicolumn{2}{|c|}{ Survey sample firms } & \multicolumn{2}{c}{ Survey respondent firms } \\
\hline & $N$ & $\%$ & $N$ & $\%$ & $\chi 2$ & \multicolumn{2}{c}{$N$} & $\%$ \\
Other (incl. communication and service firms) & 595 & 42.3 & 206 & 41.2 & 0.2 & 85 & 44.0 & 0.2 \\
Machinery and business equipment & 143 & 10.2 & 42 & 8.4 & 1.3 & 12 & 6.2 & $3.0^{*}$ \\
Banks, insurance companies, and other financials & 142 & 10.1 & 57 & 11.4 & 0.7 & 25 & 13.0 & 1.5 \\
Retail stores & 107 & 7.6 & 36 & 7.2 & 0.1 & 9 & 4.7 & 2.2 \\
Oil and petroleum products & 74 & 5.3 & 28 & 5.6 & 0.1 & 10 & 5.2 & 0.0 \\
Drugs, soap, perfumes, and tobacco & 59 & 4.2 & 22 & 4.4 & 0.0 & 7 & 3.6 & 0.1 \\
Utilities & 57 & 4.1 & 22 & 4.4 & 0.1 & 11 & 5.7 & 1.1 \\
Construction and construction materials & 41 & 2.9 & 16 & 3.2 & 0.1 & 12 & 6.2 & $5.8^{* *}$ \\
Transportation & 41 & 2.9 & 18 & 3.6 & 0.6 & 5 & 2.6 & 0.1 \\
Food & 33 & 2.4 & 13 & 2.6 & 0.1 & 6 & 3.1 & 0.4 \\
Chemicals & 29 & 2.1 & 9 & 1.8 & 0.1 & 3 & 1.6 & 0.2 \\
Automobiles & 22 & 1.6 & 4 & 0.8 & 1.6 & 1 & 0.5 & 1.3 \\
Consumer durables & 18 & 1.3 & 6 & 1.2 & 0.0 & 1 & 0.5 & 0.8 \\
Mining and minerals & 15 & 1.1 & 8 & 1.6 & 0.9 & 3 & 1.6 & 0.4 \\
Steel works & 12 & 0.9 & 7 & 1.4 & 1.1 & 3 & 1.6 & 0.9 \\
Fabricated products & 10 & 0.7 & 4 & 0.8 & 0.0 & 0 & 0.0 & 1.4 \\
Total & 8 & 0.6 & 2 & 0.4 & 0.2 & 0 & 0.0 & 1.1 \\
\hline \hline
\end{tabular}

The chi-squared statistics test the null hypothesis that the proportion of firms in each Fama-French industry classification between Compustat firms and sample firms and between Compustat firms and respondent firms, respectively, are independent. We find that our survey sample follows a statistically similar industry distribution to our Compustat firms. We find that the construction and construction materials as well as machinery and business equipment industries are slightly more and less represented, respectively, in our survey respondents compared to the Compustat firms. $* * *, * *, *$ indicate statistical significance at the $1 \%, 5 \%$, and $10 \%$ level, respectively. 


\section{Appendix 3 (Questionnaire)}

1 - Which department is primarily responsible for the first draft of the MD\&A section in the Form 10K?

$\begin{array}{lllll}\square \text { IR } & \square \text { IR } & \square \text { Legal } & \square \text { Legal } & \square \text { Finance } \\ \text { (internal) } & \text { (external) } & \text { (internal) } & \text { (external) }\end{array}$

2 - In your most recent Form 10K, how long prior to the filing of the Form 10K did this individual or team begin the draft of the MD\&A section?
1-2 weeks
3-4 weeks
5-6 weeks
$7+$ weeks

3 - When creating the draft for the current year's MD\&A, to what degree does the primary author rely on the prior year's MD\&A as a template? Check ONLY one.

No reliance $\quad \square$ Some reliance $\square$ Strong reliance $\quad \square$ Very strong reliance

4 - Estimate the total number of hours your company collectively takes to prepare the following disclosures:
MD\&A: Hour(s)
Complete 10K: Hour(s)

5 - How involved is each department in creating the MD\&A? Describe each department's involvement on a scale of $1=$ least involved to $5=$ most involved.

Least Involved $\longrightarrow$ Most Involved

$\begin{array}{lllllll}\text { IR (Internal) } & \square \text { No involvement } & \square 1 & \square 2 & \square 3 & \square 4 & \square 5 \\ \text { IR (External) } & \square \text { No involvement } & \square 1 & \square 2 & \square 3 & \square 4 & \square 5 \\ \text { CEO } & \square \text { No involvement } & \square 1 & \square 2 & \square 3 & \square 4 & \square 5 \\ \text { CFO } & \square \text { No involvement } & \square 1 & \square 2 & \square 3 & \square 4 & \square 5 \\ \text { PR/Marketing } & \square \text { No involvement } & \square 1 & \square 2 & \square 3 & \square 4 & \square 5 \\ \text { Board } & \square \text { No involvement } & \square 1 & \square 2 & \square 3 & \square 4 & \square 5 \\ \text { Legal counsel (Internal) } & \square \text { No involvement } & \square 1 & \square 2 & \square 3 & \square 4 & \square 5 \\ \text { Legal counsel (External) } & \square \text { No involvement } & \square 1 & \square 2 & \square 3 & \square 4 & \square 5 \\ \text { External auditor } & \square \text { No involvement } & \square 1 & \square 2 & \square 3 & \square 4 & \square 5\end{array}$


6 - How many substantive revisions does the MD\&A go through before publication?

Estimate.
0
$1-2$
3-5
6-10
$11-15$
$16+$

7 - In the past year, have you utilized an external investor relations advisor? Check ONLY one.

Yes, for non-routine disclosures

(M\&A event, SEC inquiry, etc.)

Yes, for routine disclosures (10K, 10Q, comment letters, etc.)
Yes, for both non-routine and routine disclosures

$\square$ No

8 - In the past year, have you utilized an external legal counsel for the preparation of disclosure documents? Check ONLY one.

Yes, for non-routine disclosures (M\&A event, SEC inquiry, etc.)

Yes, for routine disclosures (10K, 10Q, comment letters, etc.)

9 - Does external legal counsel help prepare or review the Risk Factors disclosed in the $10 \mathrm{~K}$ ?

$\square$ Yes $\square$ No

10 - Answer if your company provides annual earnings guidance: How would you characterize the influence that the sell-side consensus forecast has on your company's annual earnings guidance (i.e. the range or point estimate provided to the market)?

Very limited $\quad \square$ Limited $\quad \square$ Neutral $\quad \square$ Strong

11 - When reporting quarterly earnings, which objective would your management generally prefer among these two options? Check ONLY one.

$\square$ Meet sell-side analyst consensus $\quad \square$ Beat sell-side analyst consensus

12 - On average over the past 4 quarters, how long prior to the quarterly conference call does the draft of the management's remarks begin being drafted?

$\square<1$ week $\quad \square$ 1-2 weeks $\square$ 3-4 weeks $\quad \square$ 5-6 weeks $\square$ 7+ weeks

13 - Does someone from the company speak with sell-side analysts or buy-side investors in advance and collect potential questions of interest?

Yes $\square$ No 
14 - What types of materials, if any, are typically prepared for presentation portion of conference calls? Check ALL that apply.

$\square$ Script of remarks $\quad \square$ Outline of remarks $\quad \square$ Presentation slides

15 - Does your company prepare responses to potential questions that might be raised during conference calls?

$\square$ Yes $\square$ No

16 - On average over the past 4 quarters, how long does the $C E O$ spend preparing for the quarterly conference call?

Hour(s)

17 - On average over the past 4 quarters, how long does the $C F O$ spend preparing for the quarterly conference call?

Hour(s)

18 - How involved is each department in drafting the introductory management remarks for conference calls? Describe each department's involvement on a scale of 1 = least involved to $5=$ most involved.

\begin{tabular}{|c|c|c|c|c|c|c|}
\hline \multirow[b]{2}{*}{ IR (Internal) } & \multirow[b]{2}{*}{$\square$ No involvement } & \multicolumn{5}{|c|}{ Least Involved $\longrightarrow$ Most Involved } \\
\hline & & $\square 1$ & $\square 2$ & $\square 3$ & $\square 4$ & $\square 5$ \\
\hline IR (External) & $\square$ No involvement & $\square 1$ & $\square 2$ & $\square 3$ & $\square 4$ & $\square 5$ \\
\hline CEO & $\square$ No involvement & $\square 1$ & $\square 2$ & $\square 3$ & $\square 4$ & $\square 5$ \\
\hline CFO & $\square$ No involvement & $\square 1$ & $\square 2$ & $\square 3$ & $\square 4$ & $\square 5$ \\
\hline PR/Marketing & $\square$ No involvement & $\square 1$ & $\square 2$ & $\square 3$ & $\square 4$ & $\square$ \\
\hline Board & $\square$ No involvement & $\square 1$ & $\square 2$ & $\square 3$ & $\square 4$ & $\square$ \\
\hline Legal counsel (Internal)/GC & $\square$ No involvement & $\square 1$ & $\square 2$ & $\square 3$ & $\square 4$ & $\square 5$ \\
\hline Legal counsel (External) & $\square$ No involvement & $\square 1$ & $\square 2$ & $\square 3$ & $\square 4$ & $\square$ \\
\hline External auditor & $\square$ No involvement & $\square 1$ & $\square 2$ & $\square 3$ & $\square 4$ & \\
\hline
\end{tabular}


19 - How would you characterize your company's preparation style for the Q\&A session? Rank using scale below.

$\begin{array}{llll}\square \text { Completely } & \square \text { Mostly } & \square \text { Mostly } & \square \text { Completely } \\ \text { improvised } & \text { improvised } & \text { scripted } & \text { scripted }\end{array}$

20 - On average over the past 4 quarters, what percent of the call do you seek to allocate for the management presentation?
$0-25 \%$
$26-50 \%$
$51-75 \%$
$76-100 \%$

21 - On average after an earnings conference call, how many calls from sell-side analysts does your company take within $\mathbf{7 2}$ hours after the conference call? Estimate.
$\square 0$
$1-2$
$\square$ 3-5
6-8
$9+$

22 - On average after an earnings conference call, how many calls from buy-side analysts/investors does your company take within 72 hours after the conference call? Estimate.
0
$1-2$
$\square$ 3-5
6-8
$9+$

23 - On average over the prior year, how many sell-side analysts have covered your company? Estimate.
$\square 0$
$1-2$
$\square$ 3-5
$\square 6-8$
$\square+$

24 - To what degree does each department seek to provide more public information to the market (i.e. disclose more detailed information about the firm's progress and profitability)? Describe each department's inclination on a scale from 1 = less disclosure to $\underline{5=\text { more disclosure. }}$

\begin{tabular}{|c|c|c|c|c|c|c|}
\hline & & \multicolumn{5}{|c|}{ Less Disclosure $\rightarrow$ More Disclosure } \\
\hline IR (Internal) & $\square$ No involvement & $\square 1$ & $\square 2$ & $\square 3$ & $\square 4$ & $\square 5$ \\
\hline IR (External) & $\square$ No involvement & $\square 1$ & $\square 2$ & $\square 3$ & $\square 4$ & $\square 5$ \\
\hline CEO & $\square$ No involvement & $\square 1$ & $\square 2$ & $\square 3$ & $\square 4$ & $\square 5$ \\
\hline $\mathrm{CFO}$ & $\square$ No involvement & $\square 1$ & $\square 2$ & $\square 3$ & $\square 4$ & $\square 5$ \\
\hline PR/Marketing & $\square$ No involvement & $\square 1$ & $\square 2$ & $\square 3$ & $\square 4$ & $\square 5$ \\
\hline Board & $\square$ No involvement & $\square 1$ & $\square 2$ & $\square 3$ & $\square 4$ & $\square 5$ \\
\hline Legal counsel (Internal)/GC & $\square$ No involvement & $\square 1$ & $\square 2$ & $\square 3$ & $\square 4$ & $\square 5$ \\
\hline
\end{tabular}



Legal counsel (External)
No involvement
$\square 1 \square 2$
$\square 3$
4
$\square 5$
External auditor
No involvement
$\square 1$
2
$\square 3$
$\square 4 \square 5$

25 - On average over the past 4 quarters, what is the approximate time between when preliminary quarterly financial results are known to senior management and when they are publicly disseminated? Estimate in terms of weeks or days.

Week(s)

$\operatorname{Day}(\mathrm{s})$

26 - On average over the past 4 quarters, what is the approximate time between when final quarterly financial results are known to senior management and when they are publicly disseminated? Estimate in terms of weeks, days, or hours.

Week(s)

$\operatorname{Day}(\mathrm{s})$

$\operatorname{Hour}(\mathrm{s})$

Thank you for your time! If you would like a copy of the results of this project sent to you, please provide an e-mail address in the space below: 